\title{
HSR mechanisms and effects on the spatial structure of regional tourism in China
}

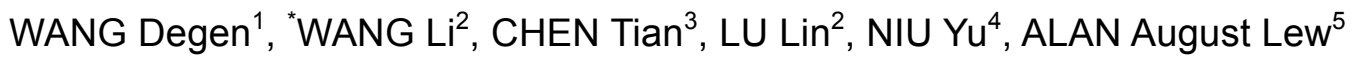 \\ 1. School of Architecture, Soochow University, Suzhou 215123, Jiangsu, China; \\ 2. College of Territorial Resources and Tourism in Anhui Normal University, Wuhu 241002, Anhui, China; \\ 3. Institute of Geographic Sciences and Natural Resources Research, CAS, Beijing 100101, China; \\ 4. Department of Tourism, Recreation and Sport Management, University of Florida, Gainesville Florida 32611, \\ USA; \\ 5. Department of Geography, Planning and Recreation, Northern Arizona University, Flagstaff Arizona 86001, \\ USA
}

\begin{abstract}
Chinese railway has entered the "HSR era", while the structure of "four vertical and four horizontal" railways for transit passengers is almost completed. Taking the Beijing-Shanghai High-Speed Rail (hereinafter referred to as HSR) as an example, this paper first explores HSR's effects on the spatial structure of regional tourist flows using the social network analysis. Next, it notes changes in the accessibility of regional transportation. After analyzing the factors including initial endowment of regional tourism resources, hospitality facilities, the density of the regional tourism transportation network, and locations, the paper discusses the mechanisms through which HSR affects regional tourist flows. The study shows the following: (1) HSR's effects on the spatial structure of regional tourist flows are manifested through the Matthew effect, the filtering effect, the diffusion effect and the overlying effect, and (2) the Matthew effect of HSR is manifested under an obvious interaction of the location, the initial endowment of tourism resources, hospitality capacity, tourist transportation network density and "time-space compression". The filtering effect of HSR is manifested for those tourism nodes without favorable location conditions, endowment of tourism resources, hospitality capacity, or tourist transportation network density and without obvious benefits from "time-space compression". Those tourism nodes that boast advantages in terms of location condition, endowment of tourism resources, hospitality capacity, tourist transportation network density and obvious "time-space compression" will become sources for the diffusion effect. HSR will strengthen the aggregation effects of tourist flow in these diffusion sources, which will thereafter diffuse to peripheral tourist areas, manifesting "aggregation-diffusion". HSR has overlapped tourists' spatial traveling range over large-scale spaces. However, the overlying effect is only generated in those tourism nodes with a favorable location condition, an endowment of tourism resources, hospitality capacity, tourist transportation network density, and obvious "time-space compression".
\end{abstract}

Keywords: spatial structure; HSR effect; mechanism; Beijing-Shanghai HSR

Received: 2015-03-30 Accepted: 2015-05-05

Foundation: Key Project of National Natural Science Foundation of China, No.41230631; National Natural Science Foundation of China, No.41271134

Author: Wang Degen (1973-), $\mathrm{PhD}$ and Professor, specialized in high-speed rail tourism and urban tourism.

E-mail:wdg713@163.com

"Corresponding author: Wang Li (1974-), E-mail: wltsr@126.com 


\section{Introduction}

As a tourist geography concept with a spatial attribute, tourist flow represents both the nerve center and the links of the tourism system (Pearce, 1981; Wu and Bao, 2002). Tourist flow manifests the spatial displacement of tourists in a region, specifically referring to the population quantity and the flow pattern of tourists from origin to destination (Yang et al., 2011). Research on tourist flow investigates the interaction between tourist origins and destinations from the perspective of space, known as O-D Study in geography, focusing on two sides: a spatial model of tourist flow and its forming mechanism. A spatial model of tourist flow mainly contains a hierarchical model of tourist flow (Lundgren, 1984), a city tourist flow model (Pearce, 1955), tourist flow's core-edge space model (PaPatheodorou, 2004; Shi et al., 2007), tourist flow's circle and layer structure model (Zhong and Zhang, 2010), and so on. As for the mechanism driving tourist flows, major factors affecting tourist flow include tourism resources (Smith, 2000; Liu et al., 2010); development level of the regional economy (Yang et al., 2011; Pearce,1995; Shi et al., 2007; Liu et al., 2010); service facilities for regional tourism, which include entertaining and shopping facilities, catering and accommodation (Lundgren,1984; Liu et al., 2010; Gearing, 1974); and regional traffic (Chew, 1987; Abeyratne, 1993; Prideaux, 2000). Moreover, the location of and options for closer destinations have effects on tourist flow as well (PaPatheodorou, 2004; Wu et al., 1997; Sun and Zhang, 2011). Among these factors, space distance and traffic accessibility are primary factors influencing the spatial structure of tourist flows (Chew, 2000; Abeyratne, 1993; Prideaux, 2000; Sun and Zhang, 2011). Space distance can convert into time distance via the degree of traffic convenience, time distance refers to the time cost through a unit space distance under the existing transportation technology condition. In other words, time distance represents the maximum accessible space distance within a unit of time under the existing transportation technology conditions. Thus, space distance is objective, while time distance varies with the transportation technology. When technological innovation creates a "space-time compression" effect, tourists' travel-time distance remains same while their space distance increases, or their space distance remains the same while their time distance shrinks. Every transportation technology breakthrough allows tourists to travel to farther destinations at a faster pace (Theobald, 1994).

High-Speed Rail (hereinafter referred to as HSR) is an important component of the worldwide "transportation revolution". HSR has become the most effective way to quickly deliver a high number of tourists. Its most prominent features are speed, safety, efficiency, and its apparent "space-time compression" effect. Through HSR's "space-time compression", tourists' space distance increases gradually while their time distance stay the same, meaning that their travel radius increases gradually. The opening of the Japanese Shinkansen brings northeastern destinations closer to tourist origins such as Tokyo and Osaka, makes travel more convenient for tourists, and presents the phenomenon of "treating Shinkansen as a corridor" (Hayashi, 2011). HSR greatly reduces the travel time from London to large cities such as Edinburgh and Glasgow in Scotland and thereby promotes the development of business and leisure tourism in cities of the UK (Givoni, 2006). The travel time from Johannesburg, South Africa, to Pretoria decreased after HSR opened, which greatly enhanced residents' desire to travel and increased passenger volume to 64,000 per day (Donaldson, 2006). 
Thus, the "space-time compression" effect produced by HSR has an obvious effect on tourists' travel distance, affecting their travel destinations selections and thereby further impacting the spatial structure of regional tourism. The opening of HSR from Perpignan, France, to Barcelona, Spain, reduced travel time but also intensified competition in the regional tourism space. Barcelona's location condition and tourism facilities concentricity are better than Perpignan's, thereby producing an HSR "siphon effect". Perpignan is just a small city with an historic memorial. Its tourism product is single and its tourism-based facilities are not perfect. Therefore, HSR led to a decline in the attraction of Perpignan for tourists and produced a high-speed rail "filter effect" (Masson and Petiot, 2009). Convenient HSR connects California's northern region, Central Valley and southern region, so that tourists can travel from Southern California to Northern California in one trip (Randolph, 2008). The Wuhan-Guangzhou HSR's effect on the evolution of the spatial structure of Hubei's regional tourism was a "double-edged" phenomenon: it strengthened the polarization effect in the core region while also enhancing the diffusion effect from the core area to the periphery (Wang, 2013).

It is found that HSR has a significant impact on the spatial structure of regional tourism. This article, taking the Beijing-Shanghai HSR as an example, compares changes in the residents' selected destinations when traveling by regular rail and by HSR from two tourist origins: Beijing and Shanghai. The paper analyses HSR's effects and the characteristics of the spatial structure of regional tourism and then analyses the mechanisms creating HSR's effect on the regional tourism spatial structure. This research has strong practical value and theoretical significance. First, it offers an in-depth exploration of the regional tourist flows' spatial structure and characteristics under HSR that will enrich and deepen the study of spatial models of domestic tourist flow. Second, a deep analysis of the mechanism driving HSR's effect on the regional travel space, in theory, fills and enriches the content of studies on tourism geography, transportation geography and behavioral geography. Third, the paper scientifically identifies HSR's impact on the spatial structure of regional tourism in China and hopes to encourage government departments, tourism businesses, and tourism research institutions to use scientific measures to help the orderly development of Chinese tourism and realize the goal of making tourism a strategic pillar of the national economy.

\section{The current situation of Chinese HSR construction and the influence of the physiogeographical environment}

When the Beijing-Tianjin Intercity Train opened on August 1st, 2008, Chinese railway officially entered the "HSR era". After this point, according to "The medium and long-term development planning of Chinese railway", Chinese HSR construction strode forward. First, the structure of "four vertical and four horizontal" railways for transit passengers are almost completed; these were built in economically developed and densely populated areas such as the Bohai Rim, the Yangtze River Delta, the Pearl River Delta, Changsha-Zhuzhou-Xiangtan, Chengdu-Chongqing, the urban agglomeration in the Central Plains, Wuhan City Circle, the Guanzhong city cluster, city groups in the West Bank of the Taiwan Straits and so on. At present, the Beijing-Shanghai dedicated passenger line, the Hangzhou-Fuzhou-Shenzhen dedicated passenger line, the Shanghai-Wuhan-Chengdu dedicated passenger line and the 
Shanghai-Kunming dedicated passenger line are all open to traffic; the Zhengzhou-Xi'an and Xi'an-Baoji HSR in the Xuzhou-Lanzhou dedicated passenger line, the Jinan-Qingdao and Shijiazhuang-Taiyuan HSR in the Taiyuan-Qingdao dedicated passenger line, the Guangzhou-Shenzhen-Hong Kong HSR except for the segment from Shenzhen north station to West Kowloon master station, the Beijing-Shijiazhuang, Shijiazhuang-Wuhan and Wuhan-Guangzhou HSR, and the Harbin-Dalian and Panjin-Yingkou HSR in the Beijing-Harbin dedicated passenger line are also all in operation. Second, three intercity rapid passenger transport systems constructed in the Bohai Rim, the Yangtze River Delta, and the Pearl River Delta regions have been further improved. Currently, dedicated lines have been opened including Beijing-Tianjin intercity railway, Chengdu-Dujiangyan intercity railway, Nanchang-Jiujiang intercity railway, Changchun-Jilin intercity railway, Hainan east ring railway, Guangzhou-Zhuhai intercity railway, Liuzhou-Nanning intercity railway, Wuhan-Xianning intercity railway, Wuhan-Huangshi intercity railway, Chengdu-MianyangLeshan dedicated passenger line, Qingdao-Rongcheng intercity railway, Zhengzhou-Kaifeng intercity railway and Zhengzhou-Jiaozuo intercity railway. Finally, the reconstruction to increase speed on existing lines and the western development of new lines has been constantly expanded. A group of lines was opened, including the Longyan-Xiamen railway, the Xiangtang-Putian railway, the Maoming-Zhanjiang railway, the Hengyang-Liuzhou railway, the Nanning-Qinzhou railway, the Qinzhou-Fangchenggang railway, the Qinzhou-Beihai HSR, the Nanning-Guangzhou railway, the Datong-Xi'an dedicated passenger line, the second double line of Lanzhou-Alashan railway, the Nanning-Guangzhou railway and the Guiyang-Guangzhou dedicated passenger line. As of October 26th, 2014, the total distance for Chinese HSR had reached 12,000 km, ranking top in the world's HSR mileage.

China's HSR network closely links eastern, central and western cities; its line coverage is broad, construction mileage is long and it confronts complex geographical environments. The Harbin-Dalian HSR through high-altitude and cold regions is one example. The climatic condition in the high-cold area is complex, and extreme weather is frequent. High altitudes and cold lead to changes in material properties and snow often covers rail equipment and can cause contact wire icing, thereby affecting the EMU's high-speed operation. The Harbin-Dalian HSR, which solves the roadbed "heave" control technology problem, is China's and the world's first HSR built in a high altitude, cold area over a long distance and with high capacity. Another example is Lanzhou-Alashan HSR, the first line built on the Qinghai-Tibet Plateau and high elevation area. It passes through the world's longest wind district, including the Yandun wind district, the hundred-mile wind district, the 30-mile wind district and the Dabancheng wind district. The hundred-mile wind district and 30-mile wind district have the strongest winds and together are one of the areas in China and in the world with the most serious potential for railway cyclones. This railway has a level I high-risk tunnel-Qilian Mountain tunnel-which represents the most difficult tunnel construction in Chinese history and currently in high-attitude areas worldwide; further, most parts in Gansu and Xinjiang pass through the Gobi desert. Still another, with the karst mountain area along the route, the entire Yichang-Wanzhou railway line is widely distributed with major unfavorable geological phenomena such as karst landscape, bedding joint, landslide, fault zones, mountain collapse and so on; the mountains are high-walled and the slopes are steep, the river valleys are deep and the terrain is extremely complex, representing a "dangerous rail- 
way in a southwest mountain area". This area is known as a "road building prohibited zone" and "the most difficult railway to build in the world". Finally, the Beijing-Shanghai HSR overcame the issue of settlement with a soft soil foundation. As one of the world's longest HSR lines and China's largest infrastructure construction project since the establishment of People's Republic of China, its technical difficulty and complexity make it suitable for a "high speed rail technology museum". The geological conditions along the Beijing-Shanghai HSR are primarily distinguished by soft soil, especially the Wuqing-Cangzhou soft soil and the Danyang-Shanghai soft soil; the buried depth changes often, the soft soil layer is thick, intensity is low, and the engineering properties are poor. In addition, in 9 hours, the Beijing-Guangzhou HSR passes through the vast snowscape of Northern and Central China, the misty rain and fog south of the Yangtze River, and the verdant green south of the Five Ridges. This route also experiences "driving from winter into spring": approximately 50\% humidity in the north to approximately $90 \%$ in the south and a temperature difference as much as $20-30^{\circ} \mathrm{C}$. Under this environment, this HSR lines overcomes the "breathing effect", the induced power fault caused by traction systems "breathing" steam because of the temperature difference.

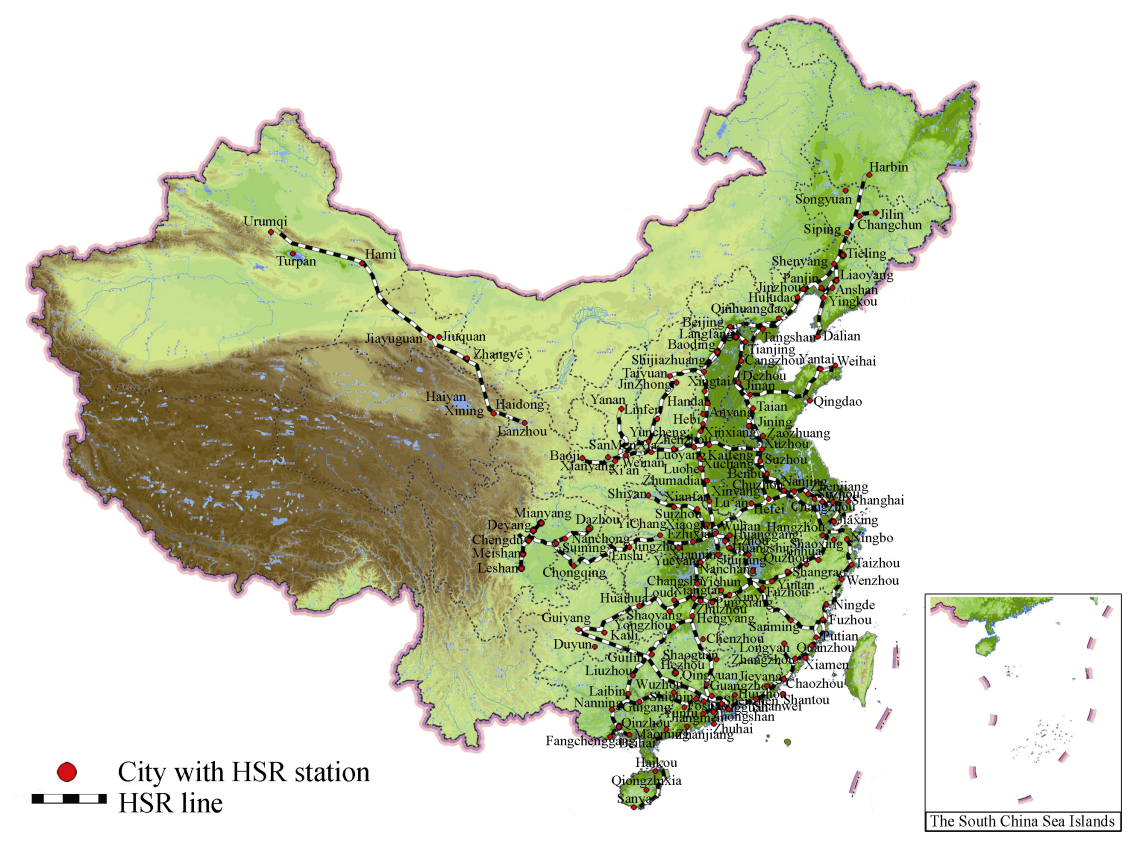

Figure 1 Construction of HSR in China

Thus, China's HSR construction has overcome complex and difficult natural geographical conditions such as cold, high-altitude districts, areas with weak foundations, karst mountain plateaus, high elevation areas, and so on. These challenges have also brought a series of impressive results in HSR construction technology such as high-speed trains, communication signals, tractive power, operations management, security monitoring, system integration, etc. An HSR technology system with Chinese features has been created, and these general technologies have entered the world's advanced rank. 


\section{Research design and data processing}

\subsection{The measure of accessibility}

First, to convert space distance into time, we need to establish the driving speeds for different types of roads. Because different types of land have different methods for commuting and different travel speeds, this article divides surface land types into land, roads and water to set the time cost. To improve accuracy, this study sets a $0.5 \mathrm{~km} \times 0.5 \mathrm{~km}$ grid size and the average minutes required to travel $1 \mathrm{~km}$ as the time cost reference. The formula is therefore $\cos t=60 / V$; in this formula, cost is the time cost and $V$ is the established speed for the various types of spatial objects. The specific speed settings are described as follows. (1) Roads are divided into railway, high-speed railway, state roads and provincial roads. According to different grades of railway mileage and speed standards in 2005 and the "People's Republic of China's Highway Engineering Technology Standard (JTGB01-2003)", speeds are set, respectively, to $90 \mathrm{~km} / \mathrm{h}, 120 \mathrm{~km} / \mathrm{h}, 80 \mathrm{~km} / \mathrm{h}$ and $60 \mathrm{~km} / \mathrm{h}$. (2) Because water areas have a certain traffic capacity, sometimes additional distance to arrive at the opposite bank, and require a greater cost than land travel, $1 \mathrm{~km} / \mathrm{h}$ is selected for the average speed (Jiang et al., 2010; Wang et al., 2010). (3) Land represents the continuous part of land excluding railway, high-speed railway, state roads, provincial roads and water. Assume that the land is homogeneous: on land, you can travel in any direction. Methods for traveling include walking, bus, taxi or private car. Through testing, a speed of $16 \mathrm{~km} / \mathrm{h}$ is established for the average speed after combining walking, bus and taxi. (4) The speed of HSR is set at $300 \mathrm{~km} / \mathrm{h}$.

To accurately calculate the accessibility of the entire space and to consider the impact of HSR's groundbreaking operation mode, this article combines network analysis with a cost-distance algorithm analysis (Jiang et al., 2010). The specific technical steps are as follows. (1) Create a road grid map containing information about the HSR stations. Designate a center, namely source $o$. (2) Via cost distance algorithm analysis, calculate the time cost $t_{o p}$ from the center to an arbitrary point $p$, that is, calculate the time $A_{o i}$ needed to travel from the center to any other HSR site $i(j)$. (3) Via network analysis, calculate the shortest time distance $B_{i j}$ from each HSR station to other stations. (4) Calculate the shortest time $C_{o i}$ from the center to each HSR station. Specifically, this method is as follows. First, find the nearest station 1 away from the center, incorporating it into the sequence $R=\left\{C_{o 1}\right\} ; C_{o 1}=A_{o 1}$. Second, find the second nearest station 2 away from the center; compare its $A_{o 2}$ and the shortest time, namely $B_{12}+C_{o 1}$, from all stations in sequence $R$ to this station by network analysis. Choose the shortest time after this comparison and incorporate it into the sequence $R=\left\{C_{o 1}\right.$, $\left.C_{o 2}\right\}$. Then find the next nearest station, that is, $C_{o 3}=\min \left\{A_{o 3}, B_{13}+C_{o 1}, B_{23}+C_{o 2}\right\}$. This method should set the shortest time from all stations to the center. (5) Calculate the time cost from each HSR station through the entire spatial grid and then obtain $N$ layers, $E_{1}, E_{2}, \ldots, E_{N}$ and the time cost from the corresponding site to the entire space, $T_{1 p}, T_{2 p}, \ldots, T_{N p}$. (6) Calculate the shortest time $T_{o p}$ from the center to all of the sites in the entire space, that is, $T_{o p}=$ $\min \left\{t_{o p}, t_{1 p}+C_{o 1}, t_{2 p}+C_{o 2}, \ldots, t_{N p}+C_{o N}\right\}$.

\subsection{The network construction of tourist flows and data processing}

Social network analysis is a scientific method used to analyze the features of a regional tourist flow network, and it mainly involves three elements: nodes, relationships and liga- 
tures. Intra-regional tourism destinations are the nodes in the social network structure; the connections between destinations are the mapping relationships from point to point in the social network structure; and the traffic aisles between destinations are the ligatures (Chen and Huang, 2006). This article uses the network structure of regional tourist flow to represent tourists flowing between the tourism nodes, and it also uses the edges of the network structure to represent the direction of tourist flow between the tourism nodes.

The data obtained through research separately constructs the matrices of a tourist flow network by using Beijing and Shanghai as tourist origins (divided into two parts-tourist flow before and after the introduction of HSR). Within these matrices, the row represents the starting point for the tourist flow, and the column represents the end. A 1 is recorded in the corresponding unit cell at each time producing tourist flow. Many analysis technologies for social networks are based on binary data, meaning that 1 represents an existing relationship, and 0 represents no relationship. Normally, the data in the original matrix would be compared with a certain data segment, more than or equal to the data segment is 1 , otherwise 0 . Therefore, choosing the proper data segment is essential for a scientific analysis. If the data segment is too large, there will be no connection, and many relationships will not be reflected; if it is too small, the relationship will be ubiquitous, and the analyzing results will have little significance. So too large or too small will prevent the detection of a network structure and an understanding of the tourism network's general trends; in addition, it will also fail to reflect the characteristics of tourist activities (Shih, 2006; Yang et al., 2007). This article, by testing and comparing, selects 3 as the data segment, makes the original matrix binary, and then obtains the tourist flow matrices before and after the introduction of HSR in Beijing and Shanghai.

\subsection{The definition of influencing factors that affect tourists' selection of travel desti- nations}

In general, tourists' spatial travel behavior is affected by many factors, generally divided into internal and external factors. Internal factors mainly include tourists' attitudes, cognition, personal income level, leisure time, social demography, etc. These factors are part of the micro-affecting mechanism, and the core of these functions is motivating the travel intentions of potential tourists. After travel intention is motivated, potential travel demands will become effective demands, and potential tourists become tourists (Yang et al., 2011). External factors mainly include tourism resources, the level of economic development, tourism service facilities, transportation, location, etc. These are part of the macro-affecting mechanism, and their effect is remarkable; in particular, spatial distance and traffic accessibility become the primary factors driving tourists to select travel destinations (Chew, 1987; Abeyratne, 1993; Prideaux, 2000; Sun and Zhang, 2011). After the opening of HSR, there is a change in the degree of influence from each factor on tourists' selected destinations with an initial endowment of regional tourism resources, hospitality facilities, the density of the regional tourism transportation network, and the space distance between tourists' origin and destination: the space distance between origin and destination is no longer the most important effect, while the initial endowment of regional tourism resources, hospitality facilities, and the density of the regional tourism transportation network become the primary factors (Wang,2012). 
In summary, this article analyzes the mechanisms driving HSR's effect on the space structure of tourist flows considering many aspects such as the initial endowment of regional tourism resources, hospitality facilities, the density of the regional tourism transportation network, the space distance between origin and destination, the location, etc. (1) The initial endowment of regional tourism resources is calculated by $T R_{j}=\sum_{i=1}^{10} W_{i} N_{i j} \cdot T R_{j} . T R_{j}$ represents cities' initial endowment of regional tourism resources; $N_{i j}$ is the quantity of world heritage, national scenic, and travel sites ranking $5 \mathrm{~A}$ and $4 \mathrm{~A}$ that are within the cities. $W_{i}$ is the weight of the different grades of tourism resources; in this article, the weight of world heritage, national scenic areas, travel areas ranking 5A and 4A are 10, 6, 4 and 2, respectively (Shi et al., 2006). If a tourist site has more than one title, we choose the highest-ranking title. The quantity of tourism resources is taken from data released by the Chinese National Tourism Administration, and the statistics are as of the end of 2011. (2) Hospitality facilities primarily include hotels, restaurants, entertainment, tourist shopping areas, and so on. The most important facility for tourists to consider is hotels, and whether a hotel can be successfully booked is an important basis on which tourists choose their destination. Considering the possibility to acquire data, we select the number of starred hotels as the index of tourist reception capacity, and these data are taken from the Statistical Yearbook of every province for 2012 or from the statistical report on the urban national economic and social development. (3) The density of the regional tourism transportation network is an important index for evaluating the advantages of a destination's traffic accessibility. This density primarily refers to the absolute ratio of the length of traffic routes to the area of the land (Huang et al., 2011).

The formula is $T N_{j}=\frac{T L_{j}}{A_{j}}$, in which $T N_{j}$ is the $j$-th urban density for the regional tourism transportation network. $T L_{j}$ is the $j$-th urban traffic route's length, given that the traffic route includes high-speed railway, state roads, provincial roads and railway as of 2011. $A_{j}$ is the $j$-th area of the city. The density of transportation network is a positive index, meaning that the larger the value is, the greater the traffic network density and the more favorable the regional traffic condition. (4) The space distance between tourists' origin and destination can generally be reflected by traffic (geography) distance and time distance. This paper primarily compares the changes in tourists' destination selection before and after the opening of HSR. Because the travel time from the origin to the same destination changes significantly before and after HSR opening, the space distance between tourists' origin and destination can be reflected by time distance.

\subsection{The selection of the tourism resource}

Taking the Beijing-Shanghai HSR as an example and taking the tourists in Beijing and Shanghai who take the bullet train and HSR as respondents, this paper analyzes how tourists choose travel destinations with HSR and without HSR (by bullet train) and then obtains the spatial distribution of tourism demand along the Beijing-Shanghai HSR. The survey mainly selects the representative scenic cities along and near the Beijing-Shanghai HSR (Figure 2). Cities along the HSR include Beijing, Langfang, Tianjin, Cangzhou, Dezhou, Jinan, Taian, Zaozhuang, Xuzhou, Suzhou, Bengbu, Chuzhou, Nanjing, Zhenjiang, Changzhou, Wuxi, 
Suzhou and Shanghai and are 18 in total. Cities near the line include Chengde, Qinhuangdao, Baoding, Shijiazhuang, Yantai, Weihai, Weifang, Qingdao, Jining, Rizhao, Lianyungang and Huangshan and are 12 in total. This study selects representative scenic regions with a high initial endowment such as world heritage sites, national scenic areas, and travel areas ranking $5 \mathrm{~A}$ and $4 \mathrm{~A}$; in addition, considering that some destinations lack these tourism resources, this study also selects level 4A tourism areas, national forest parks, and special scenic tourist spots as tourism destinations.

(a) Beijing as tourist origin

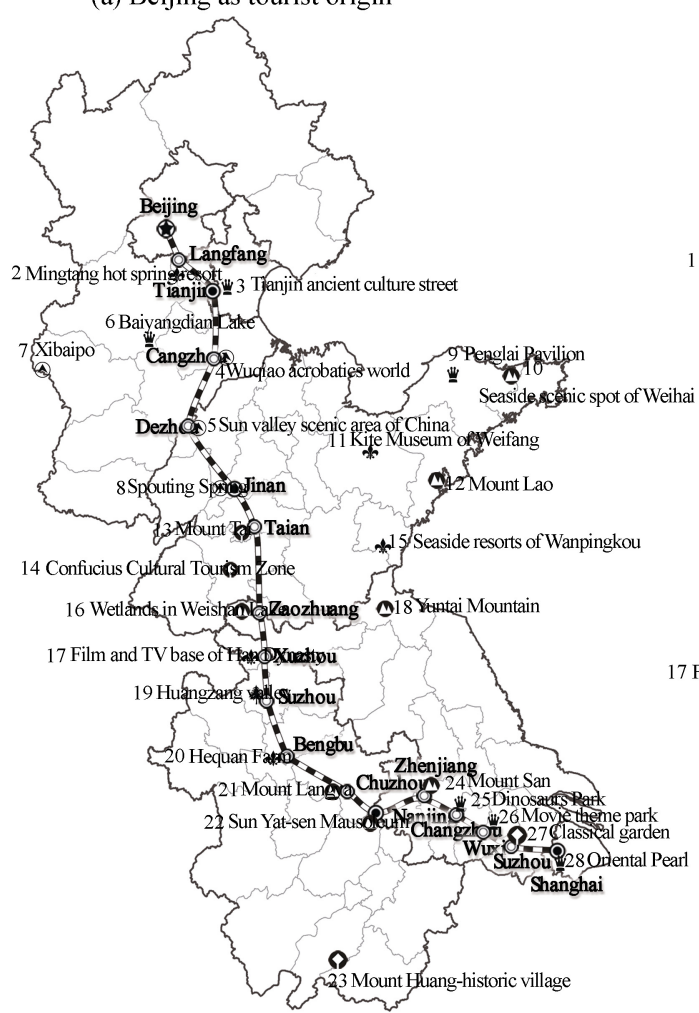

(b) Shanghai as tourist origin

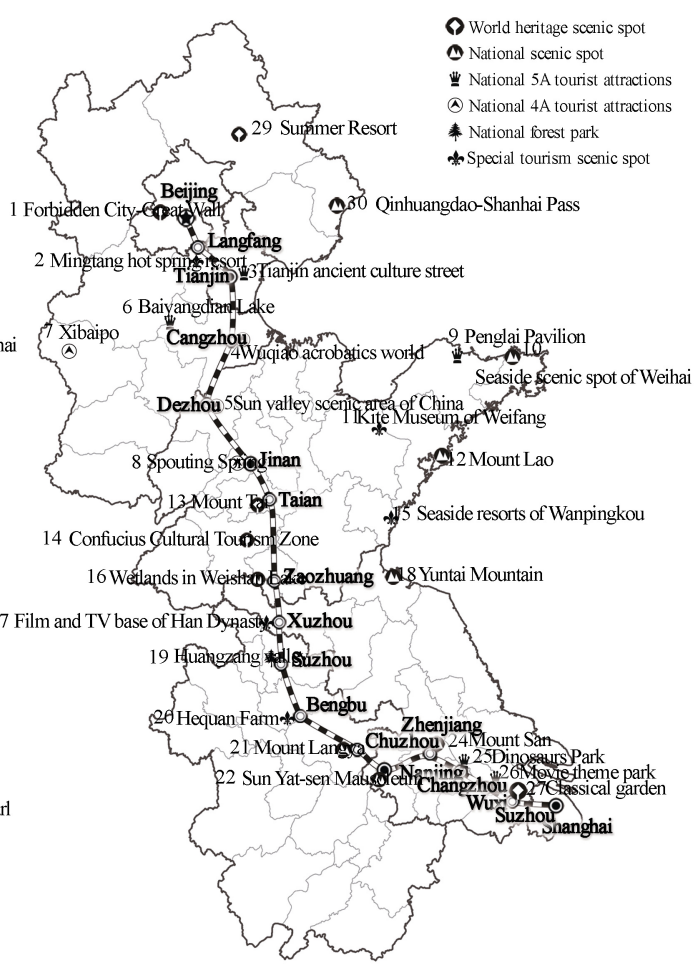

Figure 2 Spatial distribution of tourism resources along the Beijing-Shanghai HSR

\subsection{The acquisition and processing of survey data}

The "space-time compression" effect of HSR saves travel time and makes it possible for tourists to travel to distant destinations in their limited leisure time. To study a consistent time period before and after HSR's opening, this paper chooses a 3-day holiday. Representing before the introduction of HSR, Tomb-Sweeping Day from April 5th to 7th, 2011, was chosen for Shanghai and Labor Day from May 1st to 2nd, 2011, was chosen for Beijing. After HSR opened, the minor vacation of Mid-Autumn Day from September 10th to 12th, 2011, was chosen for both Shanghai and Beijing. The selected investigative sites were Shanghai's Hongqiao Railway Station, Beijing's South Railway Station, and the HSR of Shanghai-Beijing G32 and Beijing-Shanghai G111. The number of questionnaires for before and after the opening of HSR is, respectively, 549 and 349 in Shanghai, resulting in 500 and 300 
effective responses. For Beijing, the number of questionnaires is, respectively, 234 and 338, resulting in 220 and 301 effective responses. The responding rate is above $85 \%$. The questionnaires were analyzed using SPSS19.0, and the space network analysis was conducted via GIS and social networking technologies.

\section{The types and features of HSR effects on the spatial structure of regional tourist flows}

To analyze the impact of HSR on the spatial structure of regional tourist flows, this paper used the correlation analysis module in the social network analysis software Ucinet6. This module calculated the tourist flow network indexes such as degree centrality and center centrality (Table 1), as well as the tourist flow network structure (Figure 3). Comparing the spatial structure of regional tourist flows before and after the introduction of Beijing-Shanghai HSR, we analyze the HSR's effect on the spatial structure in regional tourist flows.

\subsection{The Matthew effect of HSR}

In Beijing's tourism network structure after the opening of HSR, many tourist areas presented the Matthew effect (or the so-called siphonic effect), such as Mount Tai, Jinan (please note that this location should be described as "the travel area in Jinan represented by Baotu Spring" to be concise; this more accurate description is replaced by the city in which the scenic spot is located), Nanjing, Suzhou Shanghai, and so on. The most obvious example of the Matthew effect is Mount Tai, as its three indexes all increased to different degrees: its inward and outward centrality changed from 3.85 for both before HSR to 7.69 and 11.54, respectively, after HSR, and its middle centrality increased from 0.15 to 0.92 , the fastest growth rate in all tourism nodes. These changes show that after the opening of HSR, Mount Tai's attractiveness to tourists in Beijing was greatly enhanced. The second example is Jinan. Although the degree centrality's rate of increase is not large after the introduction of HSR, at 15.39 , it is the maximum number for all tourism nodes. The advantages of competition are very obvious, as is shown by the outward centrality, which indicates that Jinan node is the center when the Beijing tourist flow diffuses to other sightseeing places near Shandong. Growing rates of degree centrality are also obvious in Nanjing, Suzhou and Shanghai, primarily seen in inward centrality growing from 3.85 for all to 7.7, 11.54 and 11.54, respectively, which shows that Nanjing, Suzhou and Shanghai are remote destinations for tourists in Beijing but that the "space-time compression" produced by the introduction of HSR has greatly enhanced their attraction for Beijing tourists (Table 1 and Figure 3).

In Shanghai's tourism network structure, Beijing, Mount Tai, Jinan, and other sightseeing locations present the Matthew effect. Again, the most obvious is Mount Tai, as its three indexes all increased to different degrees: its inward and outward degree centrality changed from, respectively, 0 and 3.85 before HSR to 19.23 and 26.92 after HSR, while its middle centrality increased from 0 to 9.85 , the fastest growth rate for all tourism nodes and the maximum number for all nodes after HSR. These changes show that after the introduction of the Beijing-Shanghai HSR, Mount Tai's attractiveness to tourists in Shanghai was greatly enhanced, making it the center of Beijing-Shanghai HSR's tourism network structure and the most important intermediate center for the northern and southern tourist flow. The next most 
Table 1 Changes of network centrality of tourist flow of Beijing and Shanghai before and after HSR

\begin{tabular}{|c|c|c|c|c|c|c|c|c|c|c|c|c|c|}
\hline \multicolumn{7}{|c|}{ The network of tourist flow in Beijing } & \multicolumn{7}{|c|}{ The network of tourist flow in Shanghai } \\
\hline \multirow{3}{*}{$\begin{array}{l}\text { Tour- } \\
\text { ism } \\
\text { nodes }\end{array}$} & \multicolumn{3}{|c|}{ Before opening HSR } & \multicolumn{3}{|c|}{ After opening HSR } & \multirow{3}{*}{$\begin{array}{c}\text { Tour- } \\
\text { ism } \\
\text { nodes }\end{array}$} & \multicolumn{3}{|c|}{ Before opening HSR } & \multicolumn{3}{|c|}{ After opening HSR } \\
\hline & \multicolumn{2}{|c|}{$\begin{array}{l}\text { Degree cen- } \\
\text { trality }\end{array}$} & \multirow{2}{*}{$\begin{array}{l}\text { Mid- } \\
\text { dle } \\
\text { cen- } \\
\text { trality }\end{array}$} & \multicolumn{2}{|c|}{$\begin{array}{l}\text { Degree } \\
\text { centrality }\end{array}$} & \multirow{2}{*}{$\begin{array}{l}\text { Mid- } \\
\text { dle } \\
\text { cen- } \\
\text { trality }\end{array}$} & & \multicolumn{2}{|c|}{$\begin{array}{l}\text { Degree } \\
\text { centrality }\end{array}$} & \multirow{2}{*}{$\begin{array}{l}\text { Mid- } \\
\text { dle } \\
\text { cen- } \\
\text { trality }\end{array}$} & \multicolumn{2}{|c|}{$\begin{array}{l}\text { Degree } \\
\text { centrality }\end{array}$} & \multirow{2}{*}{$\begin{array}{c}\text { Mid- } \\
\text { dle } \\
\text { cen- } \\
\text { trality }\end{array}$} \\
\hline & $\begin{array}{l}\text { Out- } \\
\text { ward }\end{array}$ & $\begin{array}{l}\text { In- } \\
\text { ward }\end{array}$ & & $\begin{array}{l}\text { Out- } \\
\text { ward }\end{array}$ & $\begin{array}{c}\text { In- } \\
\text { ward }\end{array}$ & & & $\begin{array}{l}\text { Out- } \\
\text { ward }\end{array}$ & $\begin{array}{c}\text { In- } \\
\text { ward }\end{array}$ & & $\begin{array}{l}\text { Out- } \\
\text { ward }\end{array}$ & $\begin{array}{c}\text { In- } \\
\text { ward }\end{array}$ & \\
\hline D2 & 0.00 & 3.85 & 0.00 & 0.00 & 0.00 & 0.00 & D27 & 3.85 & 11.54 & 0.46 & 7.69 & 3.85 & 0.00 \\
\hline D3 & 0.00 & 6.95 & 0.00 & 0.00 & 4.85 & 0.00 & D26 & 3.85 & 7.70 & 0.00 & 7.69 & 7.69 & 0.19 \\
\hline D4 & 0.00 & 3.85 & 0.00 & 0.00 & 3.70 & 0.00 & D25 & 11.54 & 11.54 & 0.92 & 5.64 & 9.12 & 0.39 \\
\hline D6 & 0.00 & 3.85 & 0.00 & 0.00 & 3.70 & 0.00 & D24 & 3.85 & 7.69 & 0.00 & 3.85 & 0.00 & 0.00 \\
\hline D7 & 0.00 & 3.85 & 0.00 & 0.00 & 3.70 & 0.00 & D22 & 7.69 & 11.54 & 0.92 & 9.74 & 13.96 & 2.68 \\
\hline D5 & 0.00 & 0.00 & 0.00 & 0.00 & 0.00 & 0.00 & D21 & 0.00 & 3.85 & 0.00 & 0.00 & 3.85 & 0.00 \\
\hline D8 & 15.23 & 3.85 & 0.77 & 15.39 & 3.85 & 0.46 & D20 & 0.00 & 0.00 & 0.00 & 0.00 & 0.00 & 0.00 \\
\hline D9 & 0.00 & 3.85 & 0.00 & 0.00 & 4.15 & 0.00 & D19 & 0.00 & 3.85 & 0.00 & 0.00 & 3.85 & 0.00 \\
\hline D10 & 0.00 & 3.85 & 0.00 & 0.00 & 4.15 & 0.00 & D18 & 0.00 & 3.85 & 0.00 & 0.00 & 7.69 & 0.00 \\
\hline D11 & 0.00 & 3.85 & 0.00 & 0.00 & 4.50 & 0.00 & D17 & 0.00 & 3.85 & 0.00 & 7.69 & 3.85 & 0.00 \\
\hline D12 & 0.00 & 3.85 & 0.00 & 3.85 & 7.69 & 0.00 & D16 & 0.00 & 0.00 & 0.00 & 0.00 & 0.00 & 0.00 \\
\hline D13 & 3.85 & 3.85 & 0.15 & 7.69 & 11.54 & 0.92 & D15 & 0.00 & 3.85 & 0.00 & 3.85 & 4.15 & 0.00 \\
\hline D14 & 0.00 & 3.85 & 0.00 & 0.00 & 4.52 & 0.00 & D14 & 0.00 & 3.85 & 0.00 & 0.00 & 7.69 & 0.00 \\
\hline D15 & 0.00 & 3.85 & 0.00 & 0.00 & 4.15 & 0.00 & D13 & 0.00 & 3.85 & 0.00 & 19.23 & 26.92 & 9.85 \\
\hline D16 & 0.00 & 0.00 & 0.00 & 0.00 & 0.00 & 0.00 & D10 & 0.00 & 0.00 & 0.00 & 3.85 & 3.85 & 0.00 \\
\hline D17 & 0.00 & 3.85 & 0.00 & 3.85 & 3.85 & 0.15 & D11 & 0.00 & 0.00 & 0.00 & 0.00 & 0.00 & 0.00 \\
\hline D18 & 0.00 & 0.00 & 0.00 & 0.00 & 3.85 & 0.00 & D12 & 0.00 & 3.85 & 0.00 & 3.85 & 7.69 & 0.08 \\
\hline D19 & 0.00 & 0.00 & 0.00 & 0.00 & 3.85 & 0.00 & D8 & 0.00 & 3.85 & 0.00 & 15.39 & 7.69 & 3.65 \\
\hline D20 & 0.00 & 0.00 & 0.00 & 0.00 & 0.00 & 0.00 & D9 & 0.00 & 0.00 & 0.00 & 0.00 & 3.85 & 0.00 \\
\hline D21 & 0.00 & 0.00 & 0.00 & 0.00 & 3.85 & 0.00 & D5 & 0.00 & 0.00 & 0.00 & 0.00 & 0.00 & 0.00 \\
\hline D22 & 0.00 & 3.85 & 0.00 & 7.69 & 7.70 & 0.35 & D7 & 0.00 & 3.85 & 0.00 & 0.00 & 0.00 & 0.00 \\
\hline D24 & 0.00 & 0.00 & 0.00 & 0.00 & 3.85 & 0.00 & D6 & 0.00 & 0.00 & 0.00 & 0.00 & 0.00 & 0.00 \\
\hline D25 & 0.00 & 0.00 & 0.00 & 0.00 & 3.70 & 0.00 & D4 & 0.00 & 0.00 & 0.00 & 3.85 & 0.00 & 0.00 \\
\hline D26 & 0.00 & 0.00 & 0.00 & 3.85 & 3.85 & 0.00 & D3 & 0.00 & 3.85 & 0.00 & 3.85 & 4.52 & 0.00 \\
\hline D27 & 0.00 & 3.85 & 0.00 & 3.85 & 11.54 & 0.11 & D2 & 0.00 & 0.00 & 0.00 & 0.00 & 3.85 & 0.00 \\
\hline D28 & 0.00 & 3.85 & 0.00 & 0.00 & 11.54 & 0.00 & D1 & 0.00 & 3.85 & 0.00 & 11.54 & 26.92 & 4.23 \\
\hline D23 & 0.00 & 3.85 & 0.00 & 0.00 & 3.85 & 0.00 & D30 & 0.00 & 0.00 & 0.00 & 0.00 & 3.85 & 0.00 \\
\hline- & - & - & - & - & - & - & D29 & 0.00 & 3.85 & 0.00 & 0.00 & 4.52 & 0.00 \\
\hline
\end{tabular}

obvious change is seen in Jinan. Its three indexes all increase to different degrees: its inward and outward degree centrality changed from, respectively, 0 and 3.85 to 15.39 and 7.69 after HSR, and its middle centrality increased from 0 to 3.65. Jinan's outward degree centrality is higher than its inward, which shows that Jinan is a center when the Shanghai tourist flow 
diffuses to other sightseeing places near Shandong. The third city of note is Beijing. Its three indexes also increase to different degrees: the inward degree centrality grows the fastest for all tourism resource nodes, from 3.85 to 26.92, making it one of the nodes with the highest inward centrality (Table 1 and Figure 3 ).

(a) Before Beijing HSR

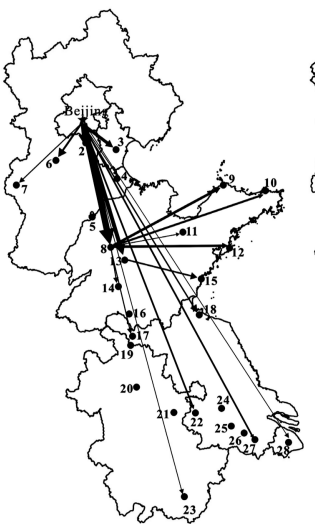

(b) After Beijing HSR

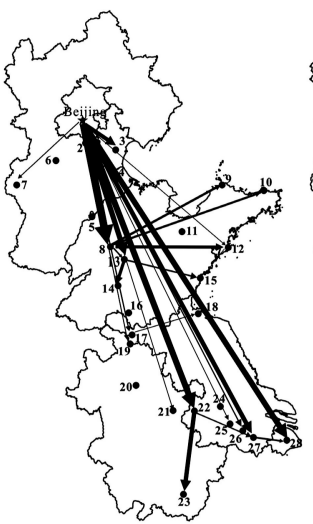

(c) Before Shanghai HSR

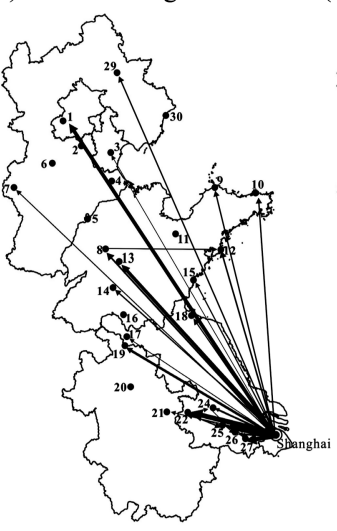

(d) After Shanghai HSR

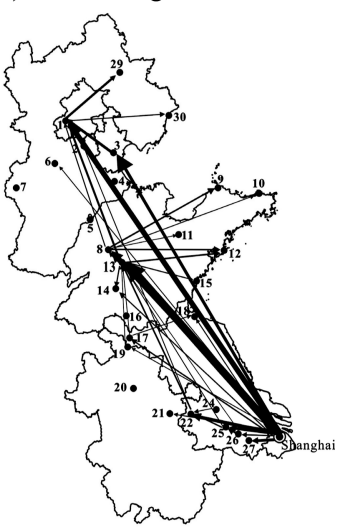

Figure 3 Impacts of Beijing-Shanghai HSR on the spatial structure of tourist flows in Beijing and Shanghai

\subsection{The filtering effect of HSR}

Although the tourism resources at some tourism nodes appreciated to a low degree or are not highly popular, they have the advantage of being located near tourist origins, which lessens the travel distance. However, the opening of HSR produced space-time compression, and low-grade tourism destinations could then easily be replaced by more remote but well-known tourism destinations in the regional tourism spatial competition, resulting in HSR's filter effect (also known as the Hall Effect). In the tourism network structure of Beijing, Langfang, Cangzhou, Baoding, Dezhou and Shijiazhuang, five tourism nodes near Beijing present a decreasing trend in inward centrality after the introduction of HSR; the tourist origin markets of these nodes are divided by some intermediate and remote high-grade popular destinations. For example, Weifang is close to Jinan node while Yantai, Weihai and other tourism destinations are more far away. Weifang therefore had certain competitiveness before HSR, but after HSR, the space-time compression from Beijing to Jinan allowed tourists the time to select Yantai and Weihai, which are far but famous, so Weifang tourism node was filtered. These five tourism nodes saw an obvious filter effect after HSR and became alternative locations (Table 1 and Figure 3).

In the tourism network of Shanghai, Zhenjiang, because it is near Shanghai, saw a substantial decreasing trend in inward centrality after the introduction of HSR, declining from 7.69 to 0 . Thus, tourist origin's markets for Zhenjiang are divided by some intermediate-range and remote high-grade tourism nodes. Second, Suzhou, Wuxi and Changzhou, which are three tourism nodes closer to Shanghai, present a slight declining trend in inward centrality after the introduction of HSR. The filtering effect for these nodes is not obvious; perhaps because the tourism resources have a high grade and reputation, they are not completely filtered and instead experience only slight filtration (Table 1 and Figure 3). 


\subsection{The diffusion effect of HSR}

In Beijing's tourism network structure, the diffusion effect is primarily manifested in three tourist locations: Jinan, Mount Tai and Nanjing (Table 1 and Figure 3). The effect is most obvious in Jinan node: after the opening of HSR, the outward centrality of Jinan rose from 15.23 to 15.39 . The growth rate is not high, but the quantity of tourist flow spreading from Jinan to Qingdao, Yantai, Weihai and so on is large, and the inward degree centrality for these three has increased from 3.85 for each to $7.69,4.15$ and 4.15, respectively. In addition, Mount Tai also received part of tourist flow caused by the diffusion from Jinan. In the places receiving diffusion, Qingdao accounts for the most, with $29.79 \%$ of the total outward diffusion from Jinan, followed by Yantai and Weihai, accounting for $27.66 \%$ and $25.53 \%$, respectively. Thus, after the introduction of HSR, Jinan's effect as a transfer and diffusing stop became more prominent. Second, the diffusion of Mount Tai is also obvious: the outward degree centrality increased from 3.85 to 7.69. The tourist flow diffused from Mount Tai to the Confucian temple-Confucian mansion-Confucian cemetery (hereinafter referred to as the three Confucians) and Rizhao grew larger. The inward degree centrality of these two tourism sites grew from 3.85 for each to 4.52 and 4.15 , respectively, the greater part $(69.23 \%)$ spreading to the three Confucians. Third, the diffusion effect of Nanjing is also obvious. The outward degree centrality increased from 0 to 7.69, mainly diffusing to the nearby Suzhou, Huangshan and Xidi-Hongcun ancient villages in southern Anhui. The tourist flow to the southern Anhui represents 94\% of Nanjing's total diffusion.

In Shanghai's tourism network structure, the diffusion effect is primarily manifested in Jinan, Mount Tai and Beijing, of which Mount Tai is most obvious: after the opening of HSR, the outward centrality of Mount Tai rose from 0 to 19.23 , and the growth rate is the highest for all of the nodes, mainly diffusing to Jinan, Beijing, Qingdao, and the three Confucians. Thus, the inward degree centrality of Jinan and Beijing significantly increased to the greatest number of diffused people traveling to these sites, respectively $31.58 \%$ and $28.95 \%$. The inward degree centrality of Qingdao rose from 3.85 to 7.69 , and the diffusion of tourist flow accounts for $13.16 \%$ and $15.79 \%$. Thus, Mount Tai became a core transfer hub after the opening of HSR. Second, the diffusion is more obvious in Jinan, where the outward centrality increased from 0 to 15.39 . The tourist flow diffusing from Jinan to Yantai, Weihai and Qingdao is greater than before HSR: the inward degree centrality of Yantai and Weihai both increased from 0 to 3.85 and of Qingdao increased from 3.85 to 7.69. Third, Beijing also shows a certain degree of diffusion; its outward centrality increased from 0 to 11.54 , mainly spreading to Chengde, Qinhuangdao and Tianjin. Of these, the greatest portion of the tourist flow spread to Chengde, accounting for $65.22 \%$ of Beijing's total diffusion, and Chengde's inward centrality increased from 3.85 to 4.52 , followed by Tianjin and Qinhuangdao (Table 1 and Figure 3).

\subsection{The overlying effect of HSR}

Urban residents' travel is greatly influenced by distance and transportation time cost; $80 \%$ of residents primarily choose medium-range destinations within $500 \mathrm{~km}$ (Wu et al., 1997). HSR's time-space compression effect greatly improved the traffic time cost; did it increase residents' travel radius? Further, whether it will turn out overlying effect when the travel 
radius of different tourist origins increased? To analyze these issues, this study takes a $60 \%$ and an $80 \%$ travel space range from tourist origins as a reference point to analyze the overlying effects. The United States tourism market scholar Ethel defines the origin, which occupies $60 \%$ of the tourism market share, as a major tourist origin market, and it plays an important role in the stable development of destination markets (Wan et al., 1998). Therefore, a $60 \%$ travel range from the main origin market becomes an important base for each destination, and the $80 \%$ travel range represents the fullest extension of the overall travel rules for an origin.

Before HSR, $60 \%$ of Beijing residents had a traveling range extending to Jinan, approximately $410 \mathrm{~km}$ from Beijing, and the cumulative proportion traveling to Jinan reached $62.41 \%$. A total of $60 \%$ of Shanghai residents had a traveling range extending to Chuzhou, approximately $346 \mathrm{~km}$ from Shanghai, and the cumulative proportion traveling to Chuzhou reached $60.91 \%$. Taking Beijing and Shanghai as the centers and a $60 \%$ traveling distance as the radius, two separate circles are drawn. Taking the $80 \%$ range, Beijing residents have a traveling range extending to Zaozhuang, approximately $625 \mathrm{~km}$ from Beijing, and the cumulative proportion traveling to Zaozhuang reached $80.85 \%$. Shanghai residents have a traveling range extending to Taian, approximately $847 \mathrm{~km}$ from Shanghai, and the cumulative proportion traveling to Taian reached $82.23 \%$. Taking Beijing and Shanghai as the centers of the circle and the $80 \%$ traveling distance as the radius, only Taian and Zaozhuang were covered by the two circles, showing a superimposed effect (Figure 4a).

After HSR (Figure 4b), 60\% of Beijing residents' traveling range extended to Nanjing, approximately $1018 \mathrm{~km}$ from Beijing, and the cumulative proportion traveling to Nanjing reached $70.3 \%$; compared with before HSR, the travel radius expanded outward $608 \mathrm{~km}$ and the flow increased $148 \%$. Meanwhile, $60 \%$ of Shanghai residents have a traveling range that extends to Taian, approximately $847 \mathrm{~km}$ from Shanghai, and the cumulative proportion traveling to Taian reached $64.83 \%$, with a travel radius expanding outward $501 \mathrm{~km}$ and tourist flow increasing 145\%. Taking Beijing and Shanghai as the centers, the two circles have shifted from being separated before HSR to overlapping after HSR; in other words, the two circles have an overlying section that includes seven tourism nodes: Nanjing, Chuzhou, Bengbu, Suzhou, Xuzhou, Zaozhuang, and Taian. Seen from the $80 \%$ range, the travel range of Beijing residents extended to Suzhou, approximately $1257 \mathrm{~km}$ from Beijing, and the cumulative proportion traveling to Suzhou reached $84.21 \%$. The travel radius expanded outward $632 \mathrm{~km}$ and tourist flow increased 101\% compared with before HSR. The travel range of Shanghai residents extended to Tianjin, approximately $1198 \mathrm{~km}$ from Shanghai, and the cumulative proportion of tourist flow reached $83.47 \%$; thus the travel radius expanded outward $41.44 \%$. The overlying section of the two circles includes 15 tourism nodes: Suzhou, Wuxi, Changzhou, Zhenjiang, Nanjing, Chuzhou, Bengbu, Suzhou, Xuzhou, Zaozhuang, Taian, Jinan, Dezhou, Cangzhou, and Tianjin, and a much greater tourist flow.

Therefore, before the introduction of HSR, the $60 \%$ travel range extends approximately $350-450 \mathrm{~km}$, which is a short to intermediate-range, and the $80 \%$ travel range extends approximately $600-850 \mathrm{~km}$, which is an intermediate to long-range. After the introduction of HSR, the $60 \%$ travel range extends to $840-1000 \mathrm{~km}$, greater than the $80 \%$ travel range before HSR, while the $80 \%$ travel range extends to $1200-1300 \mathrm{~km}$, representing a significant increase over the $500 \mathrm{~km}$ determined by earlier scholars. Thus, HSR's time-space 

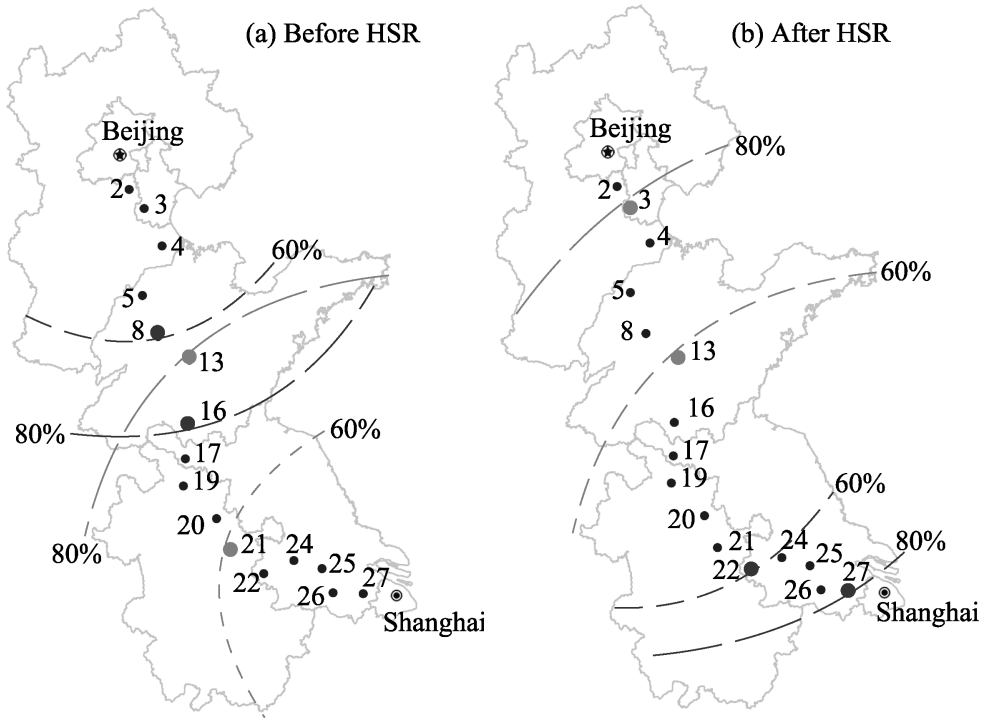

Figure 4 Comparison of the $60 \% \& 80 \%$ traveling spatial range before and after HSR opening

compression effects have an important impact on residents' selection of intermediate and long-range destinations.

Further research has found that although there are many superimposed tourism nodes, not every tourism node is preferred by tourists. It can be seen from Beijing and Shanghai HSR's tourist flow network (Table 1 and Figure 3) that, in the $60 \%$ travel range, only three tourism nodes, Jinan, Mount Tai (Taian) and Nanjing, have a high degree centrality, showing an obvious overlying effect. Other tourism nodes have a more average result for degree centrality and do not present an overlying effect. In the $80 \%$ travel range, only five tourism nodes, Jinan, Mount Tai, Nanjing, Suzhou, and Tianjin, have a high degree centrality, suggesting that these five tourism nodes show an overlying effect after the introduction of HSR.

In conclusion, the HSR effect on the spatial structure of regional tourist flow is manifested through the Matthew effect (the siphoning effect), the filtering effect (the hall effect), the diffusion effect and the overlying effect. Why does HSR lead the spatial structure of tourist flow to exhibit these types of features? This paper will give an in-depth analysis of the mechanisms behind HSR's effect on the spatial structure of regional tourist flow considering the following various influencing factors, e.g., the initial endowment of regional tourism resources, the hospitality facilities, the density of the regional tourism transportation network, the space distance between the tourists' origin and destination (accessibility variation), the location, etc.

\section{The mechanism of the HSR effect on spatial structure of regional tourism}

\subsection{The mechanism of HSR's Matthew effect}

It can be seen from the tourism network space of Beijing that after the opening of HSR, many tourist areas presented the Matthew effect, such as Jinan, Mount Tai, Nanjing, Suzhou, 
Shanghai, and so on. Seen in Figures 5a and 5b, which show the space distribution of selected destinations for Beijing tourists before and after HSR opened, the travel shares for the 5 destinations are all very high: before HSR, the shares of the five destinations, respectively, are $6.67 \%, 9.32 \%, 3.33 \%, 5 \%$ and $3.67 \%$, ranking No. 4, No. 2, No. 14 , No. 9 and No. 12 of all destinations. After HSR, the shares of the five destinations, respectively, are $11.07 \%$, $10.08 \%, 13.83 \%, 8.3 \%$ and $10.87 \%$, in all tourism destinations ranking No. 2 , No. 4 , No. 1 , No. 6 and No. 3. Thus, after the opening of HSR, the shares and the rank of the five destinations in terms of travel demand show an upward trend.

Shanghai is the endpoint of the Beijing-Shanghai line. Its economy is developed, and the urban environment is superior. The modern city landscape represented by Oriental Pearl and the business conference resources of Expo Park offer a strong endowment, ranking 6th in all tourism areas. Shanghai is an important traffic hub in China; traffic network density has reached 6.652, ranking first in all tourism areas, which is convenient for tourists' space flow. The value of tourism service facilities for Shanghai is also very high; it has 298 starred hotels, ranking first in all tourism areas (Figures 5c, 5d, and 5e). Before the opening of HSR, Shanghai was in a range above 7 hours of the isochronous circle of Beijing traffic, and travel time from Beijing to Shanghai was 10 hours. After the introduction of HSR, Shanghai shifted into the 3-5 hour range of the isochronous circle of Beijing traffic, and its travel time decreased to 5 hours (Figures $5 \mathrm{a}$ and $5 \mathrm{~b}$ ). The effect of time-space compression is very obvious. Influenced by composite factors, meaning a high tourism resource endowment, a dense transportation network in the tourism area, and strong tourism reception service facilities, the attraction of Shanghai to Beijing tourists was greatly enhanced, and the tourism demand increased by $196.45 \%$; thus, the Matthew effect is very obvious.

Jinan and Nanjing are the central terminal stations in the Beijing-Shanghai HSR as well as the provincial capital cities; namely, they represent the political, economic, and transportation centers of Shandong and Jiangsu, respectively, so the comprehensive city environments are better. For Jinan, the initial endowment of regional tourism resources is not strong, ranking just 20th in all tourism areas, but its tourism reception service facilities' absolute capacity is high, ranking 6th in all tourism areas. The city's transportation is developed, and the transportation network density is 1.246, ranking 9th; in the isochronous circle of Beijing traffic. Jinan shifted from a 3-5 hour range before HSR to 3 hours after HSR, becoming a destination for one-day travel from Beijing. Therefore, after HSR, the travel demand from Beijing to Jinan rose significantly, with a growth rate reaching $66.05 \%$, presenting the Matthew effect. Nanjing has world heritage represented by the Ming Emperor's Mausoleum and national landscape sites represented by Zhongshan Scenic Spot, so the initial endowment of resources is high, ranking 4th in all tourism areas. At the same time, Nanjing's absolute capacity for tourism reception is also high, ranking 5th in all tourism areas; the traffic network density has reached 1.397, ranking 6th. In the isochronous circle of Beijing traffic, Nanjing shifted from a 7-hour range before HSR to 3-5 hours after HSR, and the travel time decreased from 7.8 hours to 3.3 hours; thus, time-space compression is obvious. After the introduction of HSR, the growth rate of tourism demand reached $314.9 \%$; therefore, the Matthew effect is also very obvious (Figure 5). 


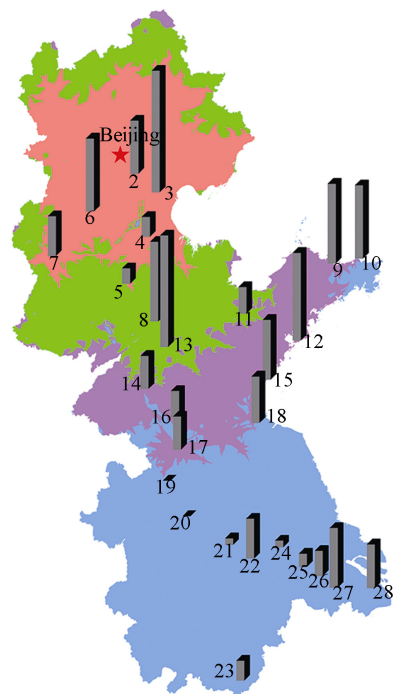

(a) Spatial distribution of Beijing tourism destination choice before HSR

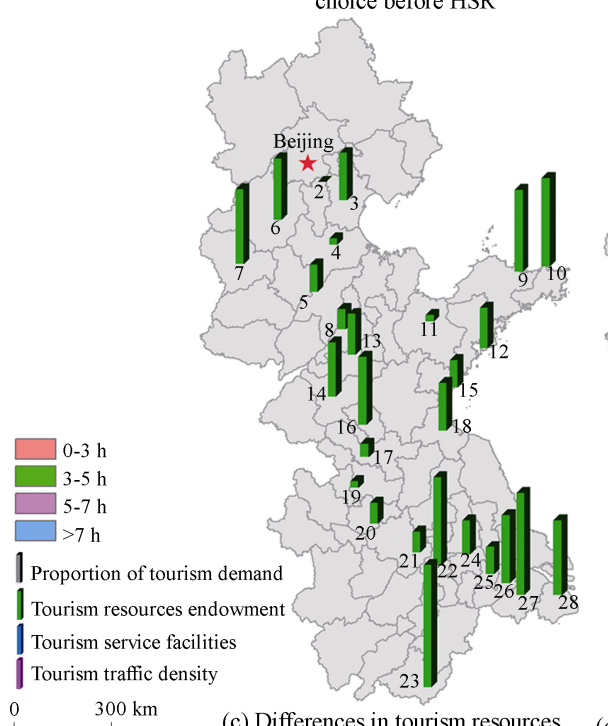

(c) Differences in tourism resources endowment

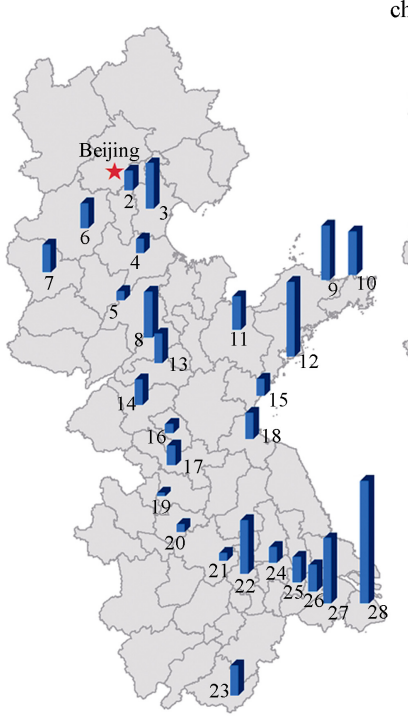

(d) Differences in tourism service facilities

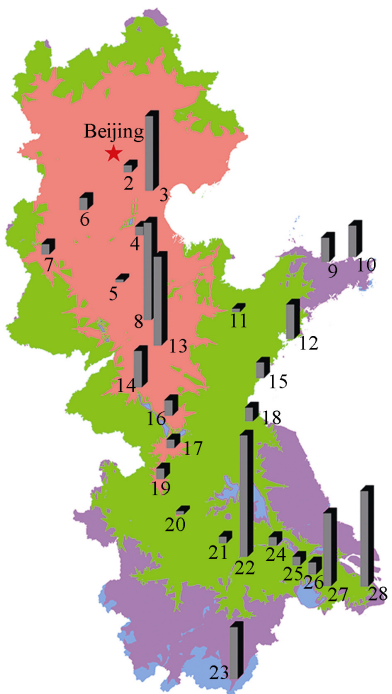

(b) Spatial distribution of Beijing tourism destination choice after HSR

Figure 5 Influencing factors and changes in Beijing travelers' spatial distribution before and after HSR opening

Mount Tai and Suzhou are famous tourism destinations on the Beijing-Shanghai line. Mount Tai's tourism resource endowment is very high; in addition, the tourism service facilities and the transportation network density of Taian, where Mount Tai is located, are ranked 11th in all tourism destinations; in the isochronous circle of Beijing traffic, Mount Tai changes from a 3-5 hour range before HSR to within 3 hours after HSR, becoming a one-day destination for Beijing tourists. Therefore, before the opening of HSR, Mount Tai already had strong appeal for Beijing tourists, with $9.32 \%$ of travel, only following Tianjin; after HSR, travel demand increased to $10.08 \%$, showing a typical Matthew effect. Suzhou encompasses classical gardens of world heritage and the Taihu Lake National Scenic Area; its resource endowment is very high in all tourism destinations, ranking $2 \mathrm{nd}$. The tourism 
service reception facility level in Suzhou is very high, ranking 2nd in all tourism destinations, just after Shanghai; the traffic network density reached 1.745, ranking 2nd just after Shanghai. In the isochronous circle of Beijing traffic, Suzhou changed from the 7-hour range before HSR to 3-5 hours after HSR, and travel time reduced from 9.3 hours to 3.9 hours; the effect of time-space compression is very obvious. Influenced by these composite factors, the attraction of Suzhou to Beijing tourists is greatly enhanced, and the increasing rate of tourism demand reached 66\%; thus the Matthew effect is very obvious (Figure 5).

It is known from the tourism network space of Shanghai that after the opening of HSR, many tourism areas presented the Matthew effect, such as Beijing, Jinan and Mount Tai. As seen in Figures $6 \mathrm{a}$ and $6 \mathrm{~b}$, before HSR, the shares of the three destinations, respectively, were $7.56 \%, 3.62 \%$, and $6.69 \%$, ranking No. 4 , No. 8 and No. 5 in all destinations; after HSR, the shares of the three destinations, respectively, were $16.08 \%, 7.49 \%$ and $13.7 \%$, in all tourism destinations ranking No. 1, No. 3 and No. 2. Thus, after the opening of HSR, the shares and the ranks of the three destinations' travel demand show an upward trend.

Of the three tourism destinations, Beijing is the endpoint of the Beijing-Shanghai line, and its urban environment is superior, having six world heritage sites represented by the Palace Museum and the Great Wall. The tourism resource endowment is very high, ranking first in all tourism destinations; the traffic network density has reached 2.816, also ranking first in all tourism destinations. Furthermore, the level of Beijing's tourism service facilities is also very high, again ranking first in all tourism destinations (Figures 6c, 6d, and 6e). Before HSR, Beijing was in the above 7-hour range of the isochronous circle of Shanghai traffic, with a 10-hour travel time, but after the introduction of HSR, Shanghai shifted into the 3-5 hour range of the isochronous circle of Shanghai traffic, and its travel time decreased to 5 hours (Figures 6a and 6b). The effect of time-space compression is very obvious. Influenced by the composite factors, meaning a high tourism resource endowment, a dense transportation network in the tourism area, and strong tourism reception service facilities, the attraction of Beijing to Shanghai tourists is greatly enhanced, and the rate of increase for tourism demand reached $112.78 \%$; thus, the Matthew effect is very obvious.

As mentioned before, Jinan has some advantages in terms of location, transportation and hospitality facilities, etc., while the tourism resource endowment of Mount Tai is extremely strong, and its transportation and reception facilities also have certain advantages. In the isochronous circle of Shanghai traffic, Jinan and Mount Tai shifted from the range above 7 hours before HSR to 3-5 hours after HSR, and the respective travel times, respectively, became 2.8 hours and 2.6 hours; time-space compression is therefore significant. Moreover, their attraction to Shanghai tourists was greatly enhanced, and the increasing rate of tourism demand increase reached $107 \%$ and $104.88 \%$; thus the Matthew effect is very obvious (Figure 6).

To sum up, the tourism nodes producing the Matthew effect after the introduction of HSR can be divided into three categories. The first is the endpoint destination, mainly Beijing and Shanghai. The location, the initial endowment of regional tourism resources, the hospitality facilities and the density of the regional tourism transportation network for this type of tourism node are all among the strongest, the time-space compression is significant, and the isochronous circle compresses the range from above 7 hours to 3-5 hours. The second type is the transfer destination, represented by Jinan or Nanjing. This type of tourism node has a 


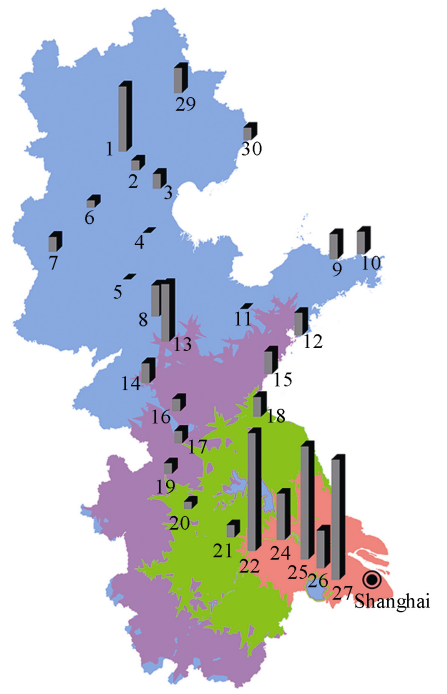

(a) Spatial distribution of Shanghai tourism destination choice before HSR

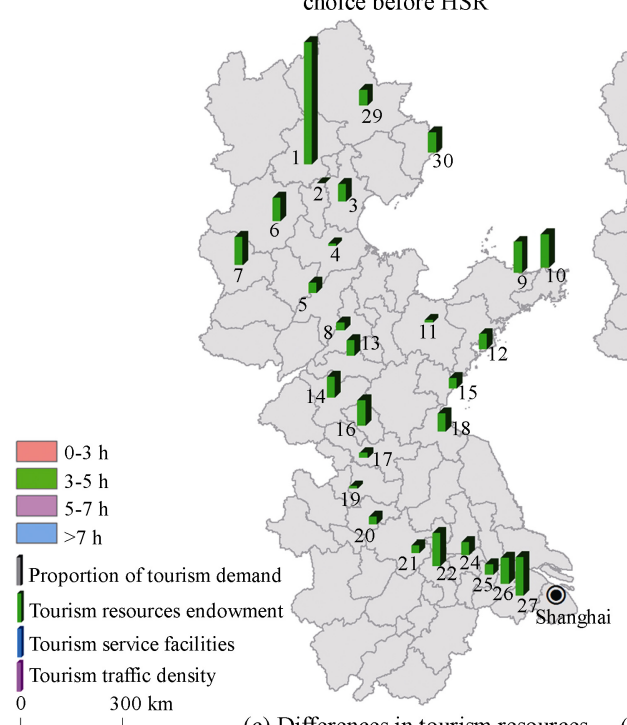

(c) Differences in tourism resources endowment

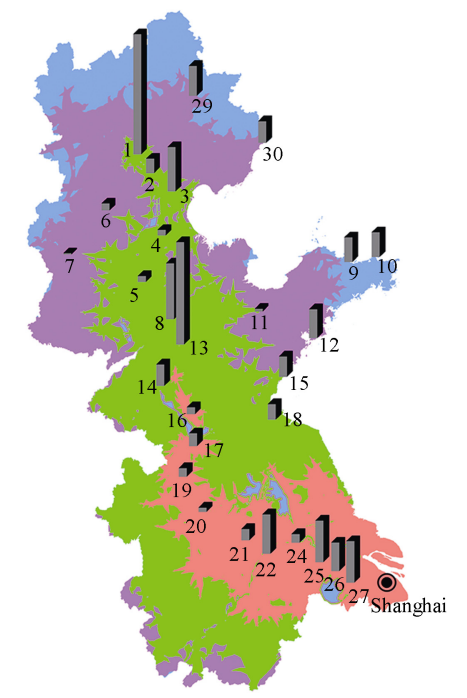

(b) Spatial distribution of Shanghai tourism destination choice after HSR

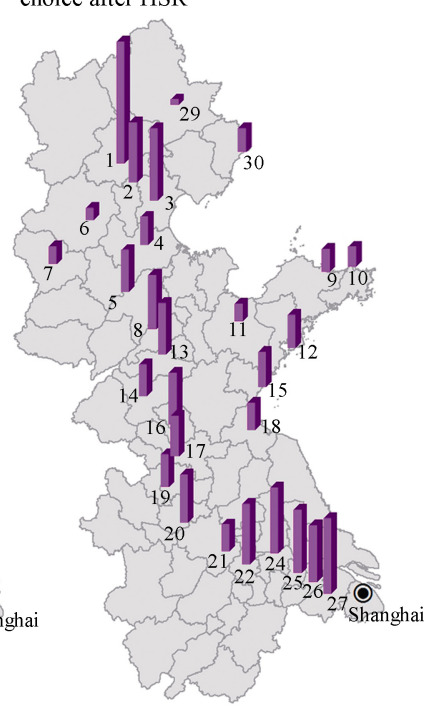

(d) Differences in tourism service facilities (e) Differences in tourism traffic density

Figure 6 Influencing factors and changes in Shanghai travelers' spatial distribution before and after HSR

very strong location, and the initial endowment of regional tourism resources, the hospitality facilities and the density of the regional tourism transportation network are all strong. Time-space compression is also obvious. Moreover, the isochronous circle compresses from the 3-5 hour range to within 3 hours or from above 7 hours to 3-5 hours. In the tourism network space of Shanghai, Nanjing is within the 3-hour range of Shanghai's isochronous circle after HSR; its time-space compression is not obvious and does not present Matthew effect. The third resource-based destination is represented by Mount Tai or Suzhou. The most outstanding feature of this type of tourism node is that the initial endowment of tourism resources is very high, based on extremely strong attractions, a location near an endpoint or a transfer city and strong tourism reception capacity and traffic networks. 
Time-space compression is obvious: the isochronous circle compresses from the 3-5 hour range to within 3 hours, or from above 7 hours to 3-5 hours. In the tourism network space of Shanghai, Suzhou is within the 3-hour range of Shanghai's isochronous circle before and after HSR; its time-space compression is not obvious and does not present the Matthew effect.

These examples show that after the opening of HSR, endpoint, transition and resourcebased destinations are all likely to experience the Matthew effect. As shown in Figure 7, destination A produces the Matthew effect and attracts more tourists influenced by five factors: the location, the initial endowment of regional tourism resources, the hospitality facilities, the density of the regional tourism transportation network and the degree of space-time compression. Among these, the endpoint type will produce a Matthew effect only when the five factors are all very obvious; a transition point will produce the Matthew effect only when the location condition is very superior and the other four factors have a stronger impact; resource-based destinations can produce the Matthew effect when the initial endowment of tourism resources is very high and other four factors all have a strong influence.

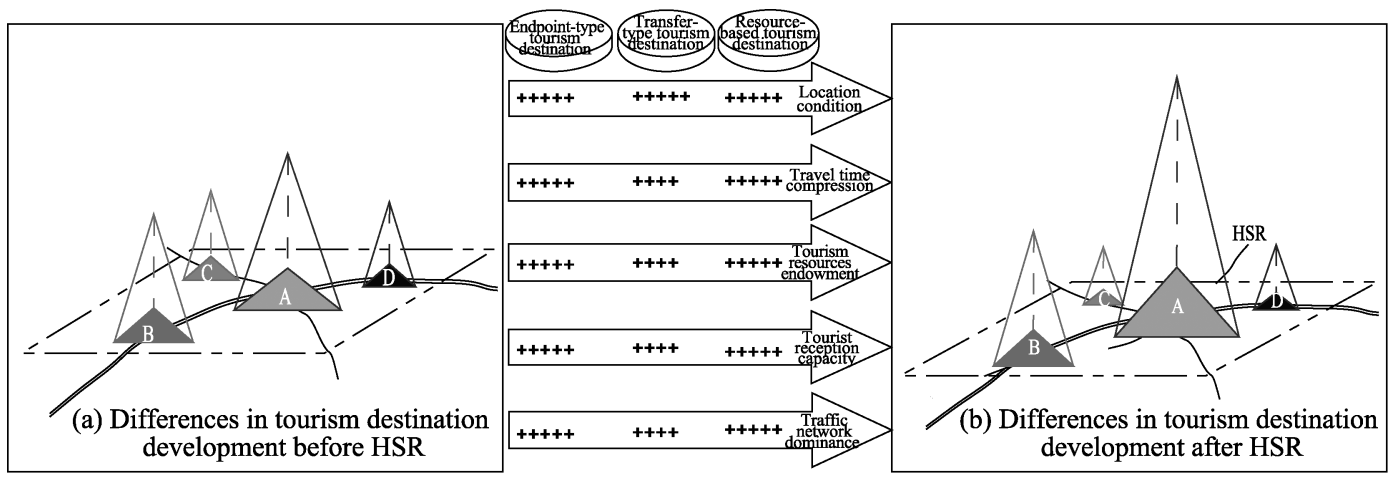

Figure 7 Mechanism of the Matthew effect for regional tourism space under the condition of HSR

\subsection{The mechanism of HSR's filtering effect}

Examining the tourism network structure of Beijing, six destinations, e.g., Langfang, Cangzhou, Baoding, Dezhou, Shijiazhuang, and Weifang, present an obvious filtering effect after HSR. These destinations' tourism resource degree is low or their popularity is not high, which is a disadvantage in the competition with high-grade and popular intermediate-range and remote destinations. However, because they are located near the Beijing tourist origin and because they have advantages in terms of location and transportation distance, some Beijing tourists selected these destinations prior to HSR; the shares of the six destinations, respectively, were $4.45 \%, 1.67 \%, 6.11 \%, 3.3 \%, 1.3 \%$ and $2.22 \%$, for a total of $19.08 \%$, occupying nearly $1 / 5$ of the total weight. After HSR, the advantages of a location near Beijing and a shorter transportation distance became disadvantages. Tourists stopped visiting low-grade and less popular destinations close to the origin due to the space-time compression of HSR; instead, they chose high-grade, popular intermediate-range and remote destinations. Therefore, the percentage selecting these destinations clearly decreased to, respectively, $0.79 \%, 0.99 \%, 1.38 \%, 1.19 \%, 0.35 \%$ and $0.4 \%$, representing $5.1 \%$ in total; the rates of decline, respectively, were $82.24 \%, 40.6 \%, 77.42 \%, 64.3 \%$ and $82 \%$, reaching $73.27 \%$ for 
the six sites in total (Figures 5a and 5b). Analyzing these individually, the initial endowment of resources is not high: apart from Shijiazhuang and Baoding, the rank of the resource endowments of Langfang, Cangzhou, Dezhou and Weifang in all tourism areas are just 27th, 25th, 18th and 24th, almost at the bottom. Seen from the tourist reception capacity, with the exception of Weifang and Shijiazhuang in the 9th and 12th rank, Langfang, Cangzhou, Baoding and Dezhou only rank 19th, 22nd, 17th and 24th, respectively, almost at the lowest positions. Considering the density of the tourism transportation network, Langfang's traffic accessibility is better due to its position close to Beijing and Tianjin and its small regional area; the traffic network density has reached 1.384, ranking 7 th. The transportation network density of Cangzhou, Baoding, Shijiazhuang, Dezhou and Weifang have not reached 1, ranking 19th, 27th, 13th, 24th and 25th in all tourism destinations, and the traffic accessibility is close to the lowest level. In the isochronous circle of Beijing traffic, Langfang, Cangzhou, Baoding and Shijiazhuang are all within the 3-hour range before and after HSR, so the space-time compression is not obvious; Dezhou shifts from the isochronous circle of 3-5 hours before HSR to within 3 hours after HSR, and travel time reduces from 2.5 hours to 1.1 hours. The tourist flow in Weifang travels through Jinan; because Jinan has changed from the 3-5 hour isochronous circle before HSR to within the 3-hour isochronous circle after HSR, Weifang's isochronous circle shifts from 5-7 hours to 3-5 hours and its travel time reduces from 4.5 hours to 2.6 hours; thus the variation is not very large (Figure 5).

In the tourism network structure of Shanghai, Zhenjiang shows a clear filtering effect after HSR. After the opening of HSR, the percentage of travel demand originating in Shanghai and traveling to Zhenjiang decreased from $5.36 \%$ before HSR to $1.15 \%$, at a rate of $78.55 \%$, shifting its rank from No. 6 to No. 21 (Figures 6a and 6b). Specifically, although Zhenjiang encompasses three national mountain scenic sites, compared with the traditional tourism resources within Nanjing, Suzhou and Wuxi in the Yangtze River Delta, it does not have strong competitiveness in terms of visibility, and its initial endowment of tourism resources ranks 17th in all tourism destinations. Zhenjiang's tourist reception capacity is only in 22nd place. Because it is close to the hub city of Nanjing, and its area is smaller, the transportation network of Zhenjiang is dense, reaching 1.541 and ranking No. 4. In the isochronous circle of Shanghai traffic, Zhenjiang is within the 3-hour range before and after HSR, and travel time decreased from 1.6 hours to 0.68 hours; thus the range of variation is not very large (Figure 6).

In addition, the opening of HSR produced a light filtering effect on some tourism destinations such as the Tianjin destination in the tourism network of Beijing, Suzhou, Wuxi and Changzhou in the tourism network space of Shanghai. After HSR, the percentage of Beijing tourists' travel to Tianjin dropped from $10.16 \%$ before HSR to $8.5 \%$ after HSR; the percentages of Shanghai tourists' travel to Suzhou, Wuxi and Changzhou dropped from 13.92\%, $4.36 \%$ and $13.08 \%$, respectively, before HSR to $5.57 \%, 3.8 \%$ and $5.57 \%$. Although these areas' share of tourism demand has decreased, in the competition for the spatial distribution of tourists' selection for travel destinations, they still have advantages. The rankings for tourism demand of these areas are all high before and after HSR, e.g., Tianjin ranks 5 th in the travel network structure of Beijing after HSR, Suzhou, Wuxi and Changzhou rank 5th, 10th and 6th, respectively, in the tourism network structure of Shanghai. The share of tourists selecting these destinations has declined, which is primarily because they are close to the 
origin. Because all are within 3 hours of the isochronous circle, the degree of time compression is not obvious; therefore, after HSR, some of the tourists shifted to intermediate-range and remote destinations. However, Tianjin, Suzhou, Wuxi and Changzhou are all strongly competitive in terms of their initial endowment of tourism resources, hospitality capacity, and tourist transportation network density, which guarantees that they still have strong attraction after HSR, generating a light filtering effect.

In summary, the filtering effect produced after HSR is primarily in destinations near to the tourist origin and also in some close to the transit hubs. The filtering effect is divided into prominent filtering destinations and light filtering destinations based on the degree. In prominent filtering destinations $\mathrm{A}$ and $\mathrm{B}$, although the initial endowment of tourism resources and hospitality capacity and the tourist transportation network density are not strong, the location advantage near the tourist origin makes $\mathrm{A}$ and $\mathrm{B}$ attractive to the one-day and weekend tour markets before HSR; A and B become hot destinations for regional tourism. Meanwhile, destination $\mathrm{D}$, located in the intermediate-range and remote areas, may have a very good endowment in terms of tourism resources, but because of its distance, its attraction to tourists with limited leisure time is not strong, becoming the cold point for regional tourism (Figure 8a). After HSR, the initial endowment of tourism resources, hospitality capacity, tourist transportation network density of the destinations A and B are not strong, while their geographic location becomes a disadvantage because of the insignificant benefits from the time-space compression degree; these factors make A and B disadvantage in terms of regional tourism competition. Most of origin markets now focus on the intermediate-range and remote destination $\mathrm{D}$ with its high initial endowment of tourism resources, strong hospitality capacity and dense tourist transportation networks. Thus, these types of markets demonstrate significant filtering effects (Figure 8b). Based on the characteristics of the tourism resources, a prominent filtering effect can be divided into a level-differential type of filtering effect and a replacement type of filtering effect. As is shown in Figure 8, A and $\mathrm{D}$ are different types of tourism resources, but A's level is lower than D's, leading to a level-differential type of filtering effect. B and D belong to the same type of tourism resources; thus they produce a replacement type of filtering effect. For the destinations withlight filtering, destination $\mathrm{C}$, which is near the origin and has a very strong initial endowment of tourism resources, hospitality capacity, and tourist transportation network density, attracts large quantities of tourists from the origin and becomes a hot spot for regional tourism (Figure 8a). After HSR, its geographic location conditions shift from an advantage

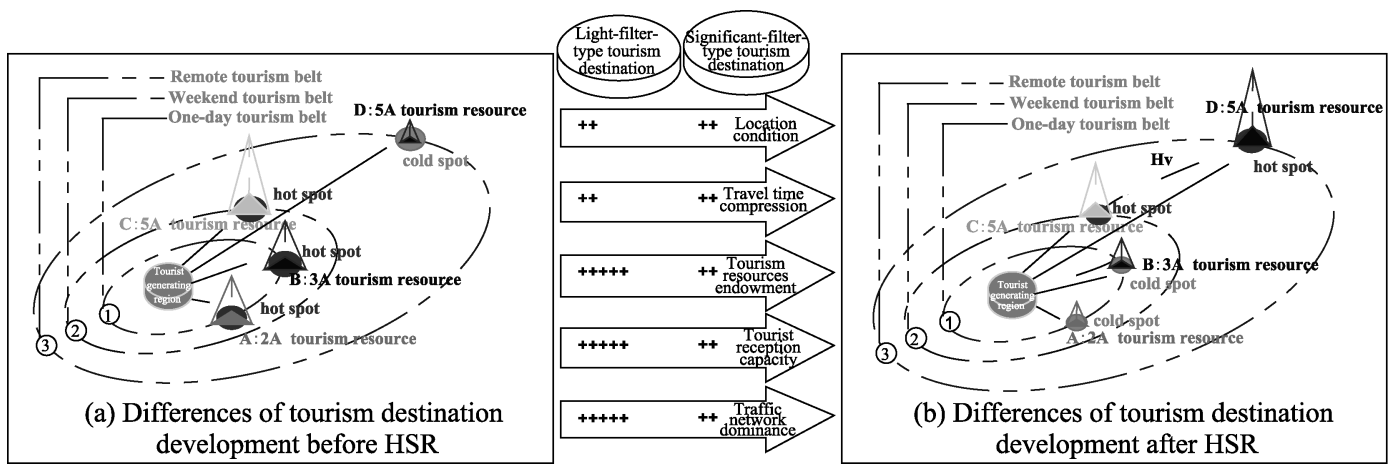

Figure 8 Mechanism of the filtering effect of regional tourism space under the condition of HSR 
to a disadvantage because of the insignificant time-space compression degree. Most of the tourists markets are replaced by destination $\mathrm{D}$ in the remote area because its initial endowment of tourism resources is high; however, because the initial endowment of tourism resources, hospitality capacity, and tourist transportation network density are all very strong for destination $\mathrm{C}$, and the filtering effect is not obvious, it remains a hot spot for regional tourism (Figure 8b).

\subsection{The mechanism of HSR's Diffusion effect}

The space-time compression effect of HSR is more obvious for a large-scale area, therefore, the more obvious the compression degree for the intermediate-range and remote travel time produced by HSR, the larger the effect on the intermediate-range and remote destinations. Chen et al. (1988) assigned large-scale area travel to remote travel because tourists often travel to high-level destinations, and subsequently, they do not generally stay in the original location to visit lower-level tourist spots. Instead, they move to other locations and visit the high-level spots at that destination (Chen and Bao, 1988). The tourism phenomenon explained by Chen et al. describes a principle of regional tourism's "core-periphery" diffusion theory: a regional core node is the source of attraction, leading to the diffusion of tourist flows to regional tourism nodes and realizing the common development of core and periphery nodes. However, there must be a precondition, namely, time must allow tourist flows in core nodes to be transferred to periphery nodes. After travel time is compressed by HSR, tourists have enough time to travel to large-scale area destinations, which makes it possible to diffuse the core nodes to the periphery nodes.

(1) The diffusing source of tourism nodes. Destinations such as Jinan, Mount Tai and Nanjing in the space of Beijing's tourism network and Mount Tai, Jinan and Beijing in the space of Shanghai's tourism network become a clear diffusing source and can be divided into three categories. The first is endpoint cities, including Beijing resorts. Seen from the preceding analysis, the initial endowment of tourism resources, hospitality capacity, and tourist transportation network density for Beijing are all extremely strong; in addition, the degree of time-space compression is significant after the introduction of HSR. The second type is the transition type of destination, including Jinan and Nanjing, who have superior locations and a stronger initial endowment of tourism resources, hospitality capacity, and tourist transportation network density; furthermore, the degree of time-space compression is more obvious after HSR. The third category is the resource type, such as Mount Tai. Its initial endowment of tourism resources is extremely strong, and the transport and reception facilities have certain advantages.

(2) The diffusing destinations of tourism nodes. In the tourism network structure of Beijing and Shanghai's HSR, the relationships between the diffusing source and the diffusing destinations can be divided into two types. The first is the radiation from the diffusing source to the diffusing destinations of nearby tourism nodes. The source of Jinan mainly diffuses to the neighboring Qingdao, Yantai and Weihai; the source of Mount Tai mainly diffuses to the surrounding Qingdao, the three Confucians, and Rizhao; the source of Nanjing mainly diffuses to the Suzhou and Huangshan ancient villages in southern Anhui; and the source of Beijing mainly diffuses to Chengde and Qinhuangdao in Hebei and Tianjin. The radiation between diffusing sources must also be considered: Jinan and Mount Tai dif- 
fuse to each other, and Mount Tai and Jinan diffuse to Beijing.

Analyzing these individually and based on the initial endowment of tourism resources for the diffusing destinations of tourism nodes, Huangshan's ancient village, traditional garden, mountain resort, and these three Confucians are world heritage sites; Laoshan in Qingdao, Qinhuangdao-Beidaihe, Panshan in Taijin are all national scenic areas; and Yantai's Penglaige, Longkou's Nanshan, Weihai's Liugong Island and the Ancient Culture Street in Tianjin are national 5-A-level tourism zones; thus the initial endowment of tourism resources for the diffusing destinations is high. Seen from the hospitality capacity of the diffusing destinations, except for Rizhao and Chengde with their relatively low hospitality capacity, other tourism nodes have relatively strong hospitality capacity, ranking top 10 in their respective tourism network structure, particularly Suzhou and Qingdao, which are on top 3. Considering the transportation advantages of the diffusing destinations of tourism nodes, the transportation network density of Suzhou Tianjin and other places are high, ranking into the top 3 places in their respective network structure; the transportation network density of the remaining tourism nodes is not very high, ranking in the middle and lower places.

Seen in terms of time-space compression degree, Suzhou and Tianjin are on the HSR, thus their compression is obvious, while the other tourism nodes are not on the HSR but are connected to diffusing sources by highway or state roads. Traffic accessibility is better, and the time-space compression of their diffusing sources is clear after the HSR; therefore the travel time from origin to diffusing destination is also compressed. In the tourism network of Beijing's HSR, Qingdao and Rizhao shifted from the 5-7 hours isochronous circle to 3-5 hours, and the three Confucians changed from the 5-7 hours isochronous circle to within 3 hours. In the tourism network of Shanghai's HSR, the three Confucians changed from the 5-7 hours isochronous circle to 3-5 hours; although the isochronous circle of the other tourism nodes did not change, the opening of HSR still shortened the travel time, with a compression ratio of $20 \%-40 \%$.

In summary, the diffusion effect produced by HSR has enhanced the link between regional core and peripheral tourism destinations and also strengthened the link between regional core destinations. The mechanism of HSR's diffusion effect is mainly characterized by a stronger attraction from the origins to the diffusing sources, with a strong aggregation of tourist flows, which then spread to the peripheral tourism areas, manifesting the "aggregation-diffusion" mode. Diffusing sources demonstrate a strong agglomeration effect. Figure 9 shows that after HSR, because the resource-based type of destination $\mathrm{O}_{1}$, transformation type of destination $\mathrm{O}_{2}$, and endpoint type of destination $\mathrm{O}_{3}$, offer advantages in location conditions, tourism resource endowment, tourism reception capacity and traffic network density as well as an obvious degree of time-space compression, they aggregate tourist flow; therefore, travel demand after HSR (perimeter triangle cone) is greatly increased compared with that before HSR (internal triangle cone). However, only when the transportation accessibility of the diffusion destinations and sources is high and the initial endowment of tourism resources, hospitality capacity, and tourist transportation network density present distinct advantages can destinations attract tourist flow from the diffusion sources. The initial endowment of tourism resources in diffusion destinations $R_{1}, R_{2}, R_{3}$ are grade 4 or grade 5 and location condition, hospitality capacity, and tourist transportation network density are grade 3 or grade 4; these levels demonstrate the strong advantages and attractiveness of these diffu- 
sion destinations, therefore, the tourist flows aggregating in the diffusion sources diffuse to these destinations.

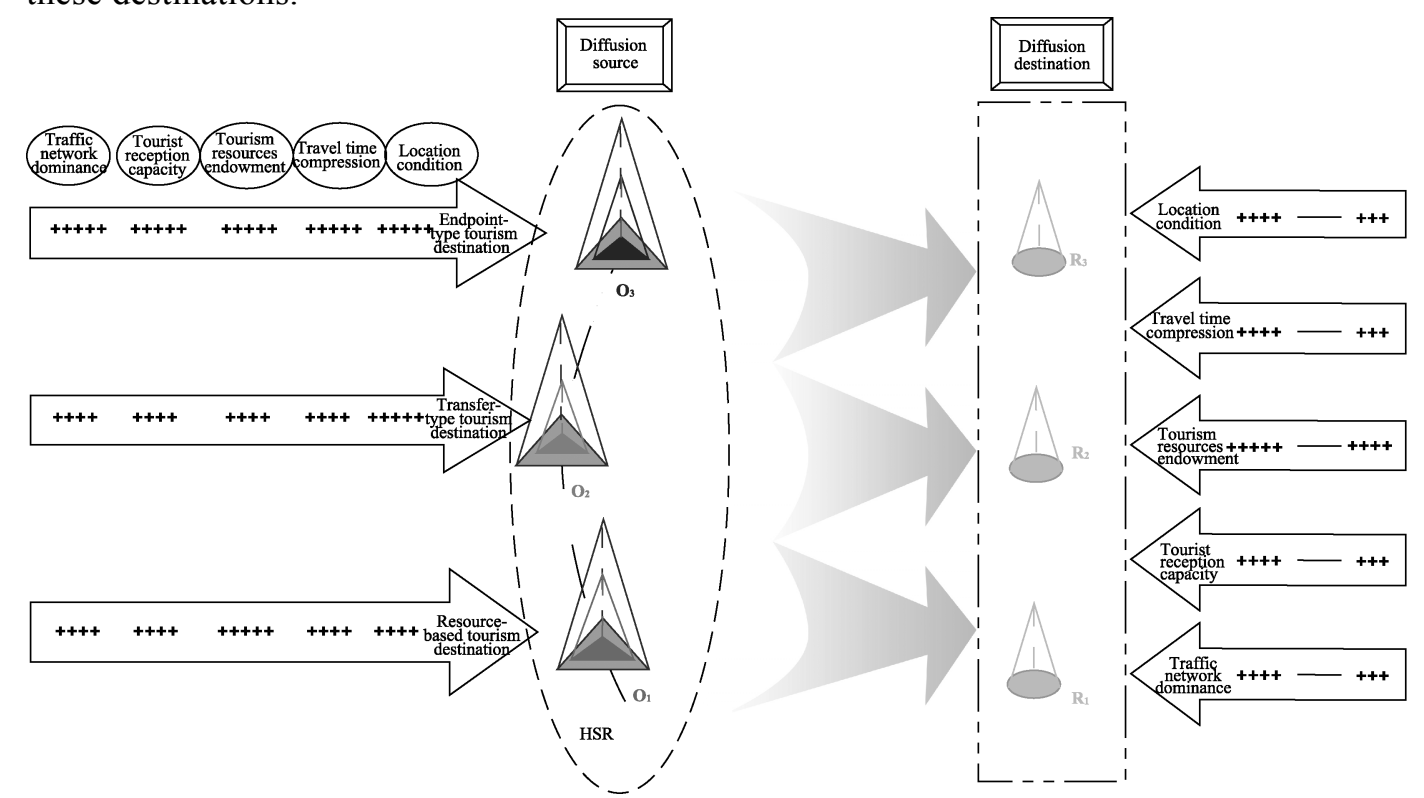

Figure 9 Mechanism of the diffusion effect for regional tourism space under the condition of HSR

\subsection{The mechanism of HSR's overlying effect}

The previous analysis showed that after HSR, in the overlying segment of Beijing and Shanghai's $60 \%$ and $80 \%$ ranges of tourism nodes, only five tourism nodes, Jinan, Mount Tai (Taian), Nanjing, Suzhou and Tianjin, produced an obvious overlying effect. As is known from Figure 5, Figure 6 and Table 2, in the 15 overlying tourism nodes of the tourism network space of Beijing and Shanghai's HSR, the rank of travel demand in Tianjin, Jinan, Mount Tai (Taian), Nanjing and Suzhou are the highest in all tourism destinations, all on top 7 , demonstrating an overlying effect. These five destinations can be divided into two categories. The first category is the transformation of tourism destinations as represented by Tianjin, Jinan and Nanjing. This type of destination has superior location conditions; in the rank of tourism resource endowment, Jinan is lower, Tianjin is in the middle, and Nanjing is higher; hospitality capacity is high for all the three, and the tourist transportation network densities are also very high, ranking on top 10. Considering the time-compression degree, the compression degrees of Jinan and Nanjing are clear; for the Beijing network, Tianjin does not show clear compression, but for the Shanghai network, it does. Another category is the resource-based destinations represented by Mount Tai and Suzhou. Their tourism resource endowments are extremely high: although Taian ranked in the middle in the initial endowment of tourism resources, the grade degree and visibility of Mount Tai are very high and its attraction is very strong. The hospitality capacity and tourist transportation network density for both of these destinations are high; Suzhou is ranked second, and Taian, where Mount Tai is located, is on top 10. The location conditions of the two places are also good, as both are near endpoint type and transformation type of destinations. Seen in terms of the time-compression degree, the compression degree of Mount Tai is clear; for the Shanghai 
network, the time-compression of Suzhou is not obvious, but for the Beijing network, it is significant. On the whole, the initial endowment of tourism resources, the hospitality capacity and tourist transportation network density of Tianjin, Jinan, Nanjing, Mount Tai and Suzhou all have obvious advantages; in terms of travel time, the overlying effect of Jinan and Mount Tai is particularly evident. In a comparison, the time-compression degrees of Tianjin in the tourism network in Beijing and of Nanjing and Suzhou in the tourism network of Shanghai are not very obvious; therefore, the overlying effect of these three destinations is lower than the overlying effects of Jinan and Mount Tai. Cangzhou, Dezhou, Zaozhuang, Xuzhou, Suzhou, Bengbu, Chuzhou, Zhenjiang, Changzhou and Wuxi are all located in the $80 \%$ overlying range of travel destinations in Beijing and Shanghai, but their initial endowment of tourism resources, their hospitality capacity and their tourist transportation network density are all not as strong, so there is no significant overlying effect.

Table 2 Comparison of the overlying tourism nodes in terms of tourist demand, influencing factors and degree of time compression

\begin{tabular}{|c|c|c|c|c|c|c|}
\hline Cities & $\begin{array}{c}\text { The rank of } \\
\text { travel de- } \\
\text { mand in } \\
\text { HSR }\end{array}$ & $\begin{array}{l}\text { The rank of } \\
\text { initial endow- } \\
\text { ment of tourism } \\
\text { resources }\end{array}$ & $\begin{array}{l}\text { The rank } \\
\text { of hospi- } \\
\text { tality ca- } \\
\text { pacity }\end{array}$ & $\begin{array}{l}\text { The rank of } \\
\text { tourist trans- } \\
\text { portation net- } \\
\text { work density }\end{array}$ & $\begin{array}{c}\text { The travel } \\
\text { time of HSR }\end{array}$ & $\begin{array}{c}\text { The travel } \\
\text { time of bullet } \\
\text { train }\end{array}$ \\
\hline Tianjin & $5 / 4$ & $12 / 12$ & $7 / 12$ & $3 / 3$ & $0.40 / 3.99$ & $0.93 / 8.90$ \\
\hline Cangzhou & $20 / 25$ & $25 / 26$ & $22 / 23$ & $19 / 19$ & $0.75 / 3.40$ & $1.80 / 8.10$ \\
\hline Dezhou & $27 / 24$ & $18 / 20$ & $24 / 25$ & $13 / 13$ & $1.10 / 3.10$ & $2.50 / 7.30$ \\
\hline Jinan & $2 / 3$ & $20 / 21$ & $6 / 6$ & $9 / 9$ & $1.40 / 2.95$ & $3.30 / 6.50$ \\
\hline Taian & $4 / 2$ & $14 / 15$ & $11 / 10$ & $11 / 11$ & $1.60 / 2.60$ & $3.80 / 6.10$ \\
\hline Zaozhuang & $13 / 2$ & $8 / 8$ & $23 / 24$ & $10 / 10$ & $2.10 / 2.00$ & $5.10 / 4.80$ \\
\hline Xuzhou & $19 / 18$ & $23 / 24$ & $18 / 18$ & $14 / 14$ & $2.30 / 1.80$ & $5.50 / 4.40$ \\
\hline Suzhou & $17 / 20$ & $26 / 27$ & $27 / 28$ & $17 / 17$ & $2.50 / 1.60$ & $6.00 / 3.90$ \\
\hline Bengbu & $26 / 26$ & $22 / 23$ & $26 / 27$ & $12 / 12$ & $2.80 / 1.40$ & $6.60 / 3.30$ \\
\hline Chuzhou & $24 / 19$ & $21 / 22$ & $25 / 26$ & $21 / 21$ & $3.15 / 1.00$ & $7.50 / 2.40$ \\
\hline Nanjing & $1 / 7$ & $4 / 3$ & $5 / 5$ & $6 / 6$ & $3.30 / 0.87$ & $7.80 / 2.00$ \\
\hline Zhengjiang & $22 / 21$ & $16 / 17$ & $21 / 22$ & $4 / 4$ & $3.50 / 0.68$ & $8.30 / 1.60$ \\
\hline Changzhou & $21 / 6$ & $19 / 18$ & $15 / 15$ & $5 / 5$ & $3.70 / 0.50$ & $8.80 / 1.10$ \\
\hline Wuxi & $16 / 10$ & $9 / 7$ & $13 / 13$ & $8 / 8$ & $3.80 / 0.37$ & $9.00 / 0.85$ \\
\hline Suzhou & $6 / 5$ & $2 / 2$ & $3 / 3$ & $2 / 2$ & $3.90 / 0.25$ & $9.30 / 0.57$ \\
\hline
\end{tabular}

Note: The data before and after "/" respectively show the tourism network space in Beijing and Shanghai

In summary, the HSR created an overlying area in the spatial range from the origins, but due to location, the initial endowment of tourism resources, the hospitality capacity, the tourist transportation network density and the degree of time-space compression, only some of the tourism nodes experienced an overlying effect. Figure 10 shows the mechanism of the regional spatial overlying effect under the HSR. Before HSR (Figure 10a), the $60 \%$ (80\%) travel range of $\mathrm{O}_{1}$ and $\mathrm{O}_{2}$ in the large-scale space represent two separate circles, respectively covering $\mathrm{D}_{1}, \mathrm{D}_{2}, \mathrm{D}_{5}$ and $\mathrm{D}_{6}$, which are near the origins, while $\mathrm{D}_{3}$ and $\mathrm{D}_{4}$ which are farther from $\mathrm{O}_{1}$ and $\mathrm{O}_{2}$, are not covered. After HSR (Figure 10b), the 60\% (80\%) travel range of $\mathrm{O}_{1}$ and $\mathrm{O}_{2}$ in the large-scale space represent two intersecting circles; the overlying parts include $D_{2}, D_{3}, D_{4}$ and $D_{5}$ because the initial endowment of tourism resources, the hospitality capac- 
ity, and tourist transportation network density of the transfer type destination $\left(\mathrm{D}_{3}\right)$ or the resource-based type of destination $\left(\mathrm{D}_{4}\right)$ are superior, and the degree of time-space compression is obvious. For these destinations, tourism demand has increased greatly after HSR, expanding beyond $\mathrm{D}_{1}, \mathrm{D}_{2}, \mathrm{D}_{5}$ and $\mathrm{D}_{6}$ and showing an obvious overlying effect. However $\mathrm{D}_{2}$ and $\mathrm{D}_{5}$, which are also in the overlying section, do not show an overlying effect because they have insignificant advantages from location, their initial endowment of tourism resources, their hospitality capacity, and their tourist transportation network.

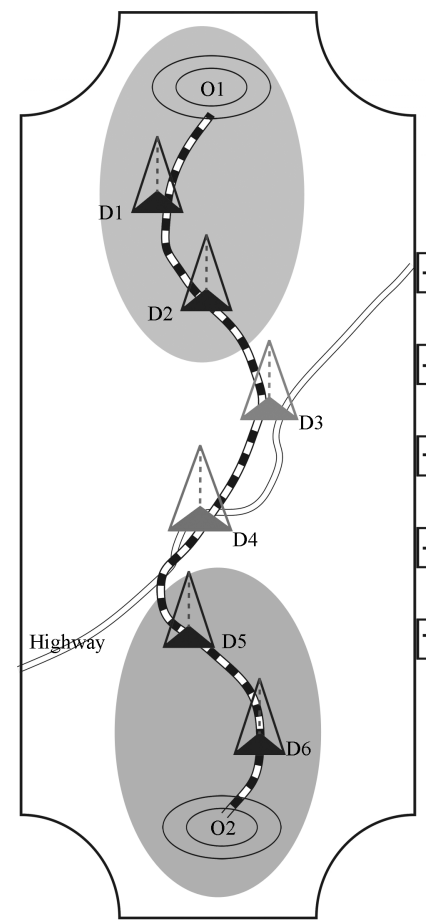

(a) Before HSR

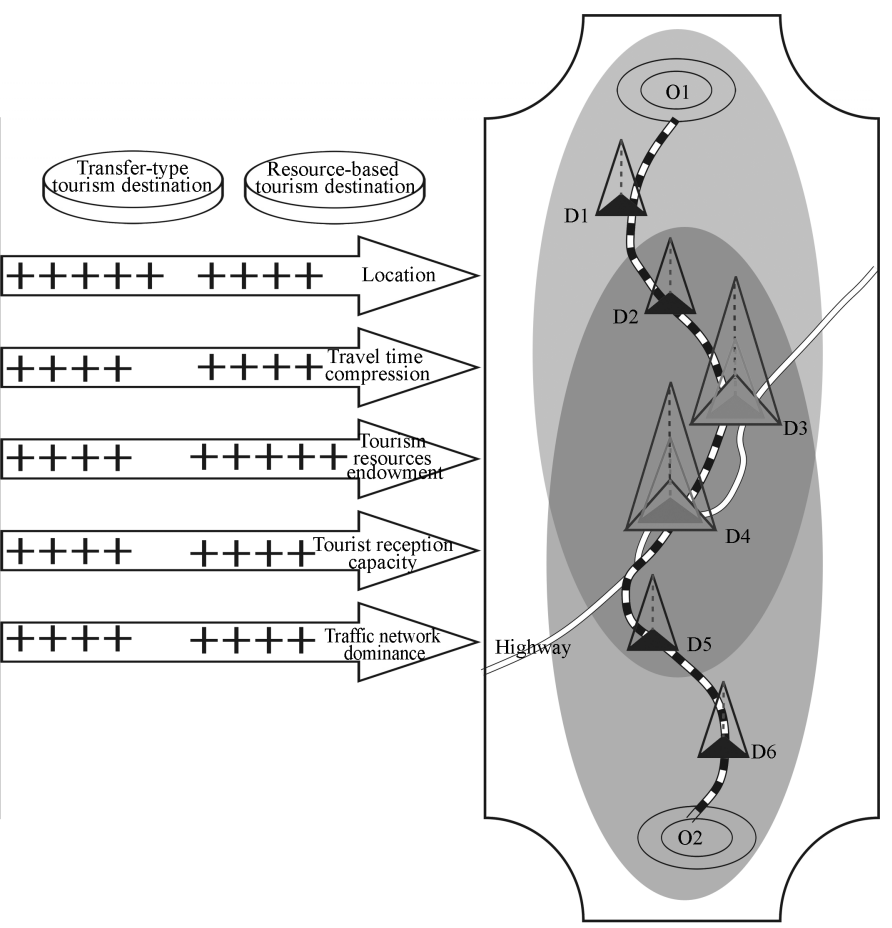

(b) After HSR

Figure 10 Mechanism of the overlying effect for regional tourism space under the condition of HSR

\section{Conclusions}

(1) The HSR effect on the spatial structure of regional tourist flows is manifested as follows. (1) In the Matthew effect, the tourist attraction of some tourism nodes with a certain level of competitiveness before HSR become stronger after HSR. (2) With the filtering effect, before HSR, some tourism nodes are near an origin and have location and traffic advantages; after HSR, these advantages become disadvantages, and time-space compression means that these tourism nodes are replaced by intermediate range and remote tourism nodes with greater attractions. (3) For the diffusion effect, after HSR, the tourist flow of some tourism nodes show clear aggregation; these aggregated flows then diffuse to other regional tourism nodes with certain attractions, which then outperform the more obvious "core-edge" type of tourist flow space. (4) With the overlying effect, HSR clearly expands the $60 \%$ or $80 \%$ spatial travel radius from the two origins; these two travel circles overlap, and some tourism nodes within the overlying range show an aggregation of tourist flows, manifested as a sig- 
nificant overlying effect.

(2) After HSR, the endpoint, transformation and resource-based types of destinations can all produce the Matthew effect. Endpoint types of destinations will produce the Matthew effect under the common influence of the initial endowment of tourism resources, the hospitality capacity, the tourist transportation network and the time-space compression degree. The transformation type of destinations must have superior location conditions while the resource-based type of destinations must have a high initial endowment of tourism resources, keeping the other four factors very strong, for these two types of nodes also experience the Matthew effect.

(3) The opening of HSR has injured some tourism nodes in the regional tourism competition. If the initial endowment of tourism resources, hospitality capacity, and tourist transportation network are not strong, and if location conditions change from advantages into disadvantages due to the opening of HSR but no significant time-space compression, then the tourist market will be replaced by intermediate range and remote tourism nodes with a strong initial endowment of tourism resources, hospitality capacity, and tourist transportation networks. This shift represents a clear HSR filtering effect.

(4) The tourism nodes whose location conditions, initial endowment of tourism resources, hospitality capacity, and tourist transportation network density all have very strong advantages and which have a significant time-space compression degree become a diffusion source. With their strong agglomeration of tourist flows, they become a stronger tourist attraction. This tourist flow then diffuses to the surrounding peripheral tourism area, representing "aggregation-diffusion". The transportation between diffusion sources and destinations is high, and the initial endowment of tourism resources, hospitality capacity, and tourist transportation network density also have certain advantages for attracting tourist flow from diffusion sources to destinations.

(5) The overlying phenomenon showed on the traveling spatial range of origins in large-scale space, but only the tourism nodes with superior location, endowment of tourism resources, hospitality capacity, tourist transportation network density and obvious space-time compression can produce overlying effect.

(6) Limited by data, this paper has only compared and analyzed the spatial distribution features of tourist flow via taking a regular train and the HSR. However, residents will also travel by air, car and many other transports, and while traveling, tourists may use a mix of HSR and other modes of transport. Therefore, considering air, train, car, and HSR system, the impact of HSR on the spatial distribution of regional tourist flow will be more complex, which requires in-depth discussion and analysis in the future.

\section{References}

Abeyratne R I R, 1993. Air transport tax and its consequences on tourism. Annals of Tourism Research, 20(2): $450-460$.

Chen Jianchang, Bao Jigang, 1988. Study of tourist behavior and its practical significance. Geographical Research, 7(3): 40-50. (in Chinese)

Chen Xiuqiong, Huang Fuca, 2006. Research on tourism spatial structure and its optimization: A network analysis. Geography and Geo-Information Science, 22(5): 75-80. (in Chinese)

Chew, J, 1987. Transport and tourism in the year 2000. Tourism Management, 8(2): 83-85.

Donaldson R, 2006. Mass rapid rail development in South Africa's metropolitan core: Towards a new urban 
form. Land Use Policy, 23: 344-352.

Gearing C E, 1974. Establishing a measure of touristic attractiveness. Journal of Travel Research, 12: 1-8.

Givoni M, 2006. Development and impact of the modern high-speed train: A review. Transport Reviews, 26: 593-611.

Hayashi Noboru, 2011. High-speed railway construction in Japan and its socio-economic impact. Journal of Urban and Regional Planning, 4(3): 132-156. (in Chinese)

Huang Xiaoyan, Cao Xiaoshu, Li Tao, 2011.The relationship between regional transport superiority and regional economic performance in Hainan. Geographical Research, 30(6): 985-999. (in Chinese)

Jiang Haibing, Xu Jiangang, Qi Yi, 2010. The influence of Beijing-Shanghai high-speed railways on land accessibility of regional center cities. Acta Geographica Sinica, 65(10): 1287-1298. (in Chinese)

Liu Fajian, Zhang Jie, Chen Dongdong, 2010. Net structure characters and causes of China's inbound tourism. Acta Geographica Sinica, 65(8): 1013-1024. (in Chinese)

Lundgren J O, 1984. Geographical concepts and the development of tourism research in Canada. Geo-Journal, 9(1): 17-25.

Masson S, Petiot R, 2009. Can the high speed rail reinforce tourism attractiveness? The case of the high speed rail between Perpignan (France) and Barcelona (Spain). Technovation, 29: 611-617.

PaPatheodorou A, 2004. Exploring the evolution of tourism resorts. Annals of Tourism Research, 31(1): 219-237.

Pearce D, 1981. Tourism Development. New York: Longman Group Limited, 67-75.

Pearce D.G, 1995. Tourism Today: A Geographical Analysis. New York: Longman Group Limited, 1-222.

Prideaux, B, 2000. The role of the transport system in destination development. Tourism Management, 21: 53-63.

Randolph S, 2008. California high-speed rail economic benefits and impacts in the San Francisco Bay Area. San Francisco: Bay Area Council Economic Institute, 10: 1-44.

Shi Chunyun, Zhang Jie, You Haimei et al., 2006. Spatial disparities of latent emissiveness of urban residents in China. Scientia Geographica Sinica, 26(5): 622-628. (in Chinese)

Shi Chunyun, Zhang Jie, You Haimei, 2007. Core-periphery spatial structure and its evolution of tourism region in Sichuan province. Acta Geographica Sinica, 62(6): 631-639. (in Chinese)

Shih Hsin-Yu, 2006. Network characteristics of drive tourism destinations: An application of network analysis in tourism. Tourism Management, 27(1): 1029-1039.

Smith M P, 2000. The destination product and its impact on traveler perceptions. Tourism Management, 21(1): 43-52.

Sun Gennian, Zhang Yu, 2011. Scenery attraction, location accessibility and trade connection: Three factors and their influences on destination choice of Japanese tourists. Geographical Research, 30(6): 1032-1043. (in Chinese)

Theobald W F, 1994. The context, meaning and scope of tourism. In: W F Theobald, Global Tourism: The Next Decade. Oxford: Butterworth-Heinemann, 139.

Wan Xucai, Ding Dengshan, 1998. An analysis on the structure of the tourist market. Human Geography, 13(3): 71-75. (in Chinese)

Wang Degen, 2012. The change characteristic and impact mechanism of regional tourism spatial structure under high speed rail conditions [D]. Beijing: University of Chinese Academy of Sciences. (in Chinese)

Wang Degen, 2013. The impact of Wuguang HSR on regional tourism spatial pattern in Hubei province. Geographical Research, 32(8): 1555-1564. (in Chinese)

Wang Zhenbo, Xu Jiangang, Zhu Chuangeng et al., 2010. The county accessibility divisions in China and its correlation with population distribution. Acta Geographica Sinica, 65(4): 416-426. (in Chinese)

Wu Bihu. Tang Junya. Huang Anmin et al., 1997. A study on destination choice behavior of Chinese urban residents. Acta Geographica Sinica, 52(2): 97-103. (in Chinese)

Wu Jinfeng, Bao Haosheng, 2002. Spatial structure mode of tourist system. Scientia Geographica Sinica, 22(1): 96-101. (in Chinese)

Yang Xingzhu, Gu Chaolin, Wang Qun, 2011. Analyze of driving force of tourist flow. Geographical Research, 30(1): 23-36. (in Chinese)

Yang Xingzhu, Gu Chaolin, Wang Qun, 2007. Urban tourism flow network structure construction in Nanjing. Acta Geographica Sinica, 62(6): 609-620. (in Chinese)

Zhong Shien, Zhang Jie, 2010. Spatial patterns of tourist flow: Problems and prospect. Human Geography, 25(2): 31-36. (in Chinese) 